\title{
Ocean deoxygenation and copepods: coping with oxygen minimum zone variability
}

\author{
Karen F. Wishner ${ }^{1}$, Brad Seibel ${ }^{2}$, and Dawn Outram ${ }^{1}$ \\ ${ }^{1}$ Graduate School of Oceanography, University of Rhode Island, Narragansett, RI 02882, USA \\ ${ }^{2}$ College of Marine Science, University of South Florida, St. Petersburg, FL 33701, USA
}

Correspondence: Karen F. Wishner (kwishner@uri.edu)

Received: 27 September 2019 - Discussion started: 28 October 2019

Revised: 31 March 2020 - Accepted: 2 April 2020 - Published: 24 April 2020

\begin{abstract}
Increasing deoxygenation (loss of oxygen) of the ocean, including expansion of oxygen minimum zones (OMZs), is a potentially important consequence of global warming. We examined present-day variability of vertical distributions of 23 calanoid copepod species in the Eastern Tropical North Pacific (ETNP) living in locations with different water column oxygen profiles and OMZ intensity (lowest oxygen concentration and its vertical extent in a profile). Copepods and hydrographic data were collected in vertically stratified day and night MOCNESS (Multiple Opening/Closing Net and Environmental Sensing System) tows $(0-1000 \mathrm{~m})$ during four cruises over a decade (20072017) that sampled four ETNP locations: Costa Rica Dome, Tehuantepec Bowl, and two oceanic sites further north (21$22^{\circ} \mathrm{N}$ ) off Mexico. The sites had different vertical oxygen profiles: some with a shallow mixed layer, abrupt thermocline, and extensive very low oxygen OMZ core; and others with a more gradual vertical development of the OMZ (broad mixed layer and upper oxycline zone) and a less extensive OMZ core where oxygen was not as low. Calanoid copepod species (including examples from the genera $\mathrm{Eu}$ calanus, Pleuromamma, and Lucicutia) demonstrated different distributional strategies (implying different physiological characteristics) associated with this variability. We identified sets of species that (1) changed their vertical distributions and depth of maximum abundance associated with the depth and intensity of the OMZ and its oxycline inflection points; (2) shifted their depth of diapause; (3) adjusted their diel vertical migration, especially the nighttime upper depth; or (4) expanded or contracted their depth range within the mixed layer and upper part of the thermocline in association with the thickness of the aerobic epipelagic zone (habitat
\end{abstract}

compression concept). These distribution depths changed by tens to hundreds of meters depending on the species, oxygen profile, and phenomenon. For example, at the lower oxycline, the depth of maximum abundance for Lucicutia hulsemannae shifted from $\sim 600$ to $\sim 800 \mathrm{~m}$, and the depth of diapause for Eucalanus inermis shifted from $\sim 500$ to $\sim 775 \mathrm{~m}$, in an expanded OMZ compared to a thinner OMZ, but remained at similar low oxygen levels in both situations. These species or life stages are examples of "hypoxiphilic" taxa. For the migrating copepod Pleuromamma abdominalis, its nighttime depth was shallow $(\sim 20 \mathrm{~m})$ when the aerobic mixed layer was thin and the low-oxygen OMZ broad, but it was much deeper $(\sim 100 \mathrm{~m})$ when the mixed layer and higher oxygen extended deeper; daytime depth in both situations was $\sim 300 \mathrm{~m}$. Because temperature decreased with depth, these distributional depth shifts had metabolic implications.

The upper ocean to mesopelagic depth range encompasses a complex interwoven ecosystem characterized by intricate relationships among its inhabitants and their environment. It is a critically important zone for oceanic biogeochemical and export processes and hosts key food web components for commercial fisheries. Among the zooplankton, there will likely be winners and losers with increasing ocean deoxygenation as species cope with environmental change. Changes in individual copepod species abundances, vertical distributions, and life history strategies may create potential perturbations to these intricate food webs and processes. Present-day variability provides a window into future scenarios and potential effects of deoxygenation. 


\section{Introduction}

Increasing ocean deoxygenation (loss of oxygen), including expansion of oxygen minimum zones (OMZs), is a potentially important consequence of global warming (Breitburg et al., 2018; Levin, 2018; Stramma et al., 2008). In the future, OMZs (oceanic depth zones of low oxygen) are predicted to expand in geographic extent and to have even lower oxygen concentrations in their centers compared to the present. The zooplankton community from the mixed layer into the mesopelagic is a key component of oceanic food webs, particle processing, and biogeochemical cycles (Robinson et al., 2010; Steinberg and Landry, 2017). From earlier work, some mesopelagic species are known to be sensitive to environmental oxygen concentration and respond to that variability by altering their distribution patterns (Wishner et al., 2018, 2013; Seibel and Wishner, 2019). If the OMZ expands on a broader scale, distributions and abundances of many zooplankton species will likely be affected, with potential consequences for oceanic ecosystems.

We previously noted the presence of zooplankton boundary layers (sharp peaks of high zooplankton biomass and abundances of certain fish and copepod indicator species) at the upper and lower edges (oxyclines) of the OMZ core at two sites (Costa Rica Dome, Tehuantepec Bowl) in the Eastern Tropical North Pacific (ETNP), as well as how the lower oxycline biomass peak shifted depth by tracking oxygen concentration (Wishner et al., 2013). These peaks of zooplankton concentration in the water column were also locations of active trophic processing (Williams et al., 2014), life history events (diapause depths) for some species (Wishner et al., 2013), and predator concentrations (Maas et al., 2014).

Here, we examine the variability of vertical distributions of copepod species living in locations with different water column oxygen profiles and OMZ intensity (lowest oxygen concentration and its vertical extent in a profile). We obtained quantitative vertically stratified zooplankton samples from the surface to 1000 or $1200 \mathrm{~m}$, with simultaneous hydrographic data, from four cruises from 2007 to 2017 at several sites in the ETNP, an oceanic region with a strong OMZ (Fiedler and Talley, 2006; Karstensen et al., 2008; Paulmier and Ruiz-Pino, 2009). The tows sampled four different geographic locations, each showing a distinctive shape of the vertical oxygen profile through the OMZ. Some sites had a narrow shallow mixed layer, abrupt thermocline, and extensive very low oxygen $\mathrm{OMZ}$ core, while others had a more gradual vertical development of the OMZ (broad upper oxycline zone of diminishing oxygen) and a less extensive OMZ core where the concentration of oxygen was not as low. On the 2017 cruise, horizontally sequenced transects and tows at three different depths within the OMZ exhibited considerable submesoscale physical and biological variability (including kilometer-scale features of oxygen); zooplankton abundance differences were associated with oxygen differences of only a few micromolar ( $\mu \mathrm{M}$; Wishner et al., 2018). Here, we fo- cus on copepod vertical distributions in order to compare species-specific responses to large-scale spatial and temporal environmental variability among the four different OMZ locations.

Many marine taxa, including zooplankton, are physiologically sensitive to the oxygen partial pressure in their environment (Childress and Seibel, 1998; Seibel, 2011; Seibel et al., 2016; Seibel and Wishner, 2019). One measure, typically viewed as an index of hypoxia tolerance, is $P_{\text {crit }}$, defined as the lowest experimentally determined partial pressure of oxygen at which an individual of a species can maintain its oxygen consumption rate $\left(\mathrm{MO}_{2}\right)$. Recent work demonstrates that hypoxia does not specifically select for a lower $P_{\text {crit }}$ but rather that the ratio of $\mathrm{MO}_{2}$ to $P_{\text {crit }}$ is a reflection of the physiological capacity to extract and transport oxygen, which is dependent on $\mathrm{PO}_{2}$ as well as a species' activity level (Seibel and Deutsch, 2019). Species living in extreme hypoxia, such as those in OMZs, have greater oxygen supply capacity than do species living in air-saturated water. As a result, measured $P_{\text {crit }}$ values are generally related to the environmental parameters (temperature, oxygen, depth) where the species occurs (Childress, 1975; Seibel, 2011). Mesopelagic species living in OMZs have the lowest measured $P_{\text {crit }}$ values among animals (Seibel et al., 2016; Thuesen et al., 1998; Wishner et al., 2018). For most of these species, hypoxia tolerance is reduced at higher temperatures ( $P_{\text {crit }}$ values are higher) because respiration increases, but one copepod species ( $\mathrm{Luci}$ cutia hulsemannae), living at the OMZ lower oxycline, has a reverse temperature response, which is adaptive in this habitat where oxygen and temperature are inversely correlated (Wishner et al., 2018). In situ abundances of some OMZ species also respond to slight environmental oxygen variations at very low oxygen concentrations $(<10 \mu \mathrm{M})$ at mesopelagic depths, corresponding to their experimentally determined physiological tolerances (Wishner et al., 2018). Here, we document oxygen and temperature ranges at the depth of maximum abundance in vertical profiles for a number of copepod species, as an indicator of the most metabolically suitable habitat for each species at the time and place of collection.

Alterations in zooplankton distributions in response to oxygen may have wider implications for ecosystem function and ultimately drive potential societal impacts (e.g., fisheries effects). Present-day comparisons among locations with different water column oxygen structure can be used as proxies to illuminate potential future effects of OMZ expansion. We analyzed zooplankton vertical distributions spatially and temporally, using key copepod species as examples, to address the following important questions about OMZ expansion effects:

1. Do mesopelagic copepod species adjust their depth distribution, especially the occurrence of boundary layers at oxyclines, in association with the shape of the vertical profile of oxygen? 


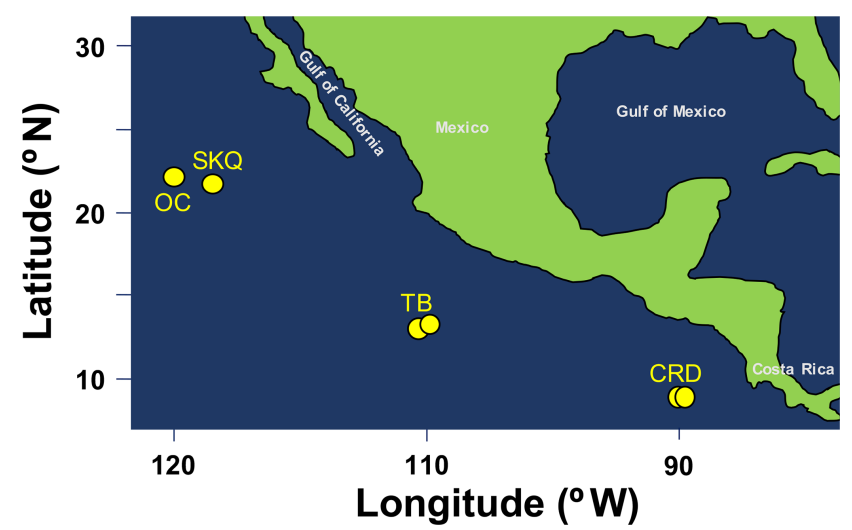

Figure 1. Map showing station locations.

2. Does the depth of diel vertical migration (DVM) for particular species change in association with OMZ thickness and oxygen concentration, or do the copepods continue to migrate to the same depth regardless of oxygen?

3. Can distributional effects of aerobic habitat compression on epipelagic copepod species be documented? Specifically, do mixed layer species have different lower depth boundaries depending on the depth and abruptness at which very low oxygen occurs?

\section{Methods}

\subsection{Sampling}

Zooplankton samples were collected in day and night vertically stratified net tows during four cruises to the ETNP (Fig. 1, Table 1). In October-November 2007 on R/V Seward Johnson and December 2008 on R/V Knorr (cruise 19502), sites at the Costa Rica Dome (CRD) $\left(9^{\circ} \mathrm{N}, 90^{\circ} \mathrm{W}\right)$ and Tehuantepec Bowl (TB) $\left(13^{\circ} \mathrm{N}, 105^{\circ} \mathrm{W}\right)$ were sampled as part of the Eastern Tropical Pacific (ETP) project. A few years later as part of the Metabolic Index Project, R/V Oceanus (cruise OC1604B) in April 2016 occupied a station (OC) farther north at $22^{\circ} \mathrm{N}, 120^{\circ} \mathrm{W}$, and the next year in January-February 2017 R/V Sikuliaq (cruise SKQ201701S) occupied a station (SKQ) at $21^{\circ} \mathrm{N}, 117^{\circ} \mathrm{W}$. These station abbreviations are used for graph labels in the figures.

At all locations, a series of vertically stratified MOCNESS (Multiple Opening/Closing Net and Environmental Sensing System) (Wiebe et al., 1985) tows, along with simultaneous hydrographic data, collected day and night zooplankton samples from depth (1000 or $1200 \mathrm{~m}$ ) to the surface (Tables 1 and S1, which is available in Wishner et al., 2019). Standard tows sampled the entire $0-1000 \mathrm{~m}$ depth range in 100 or $200 \mathrm{~m}$ intervals ( 8 or 9 nets). At most stations, additional fine-scale tows were taken over various intermediate depth ranges, usually at sampling intervals of 25,50 , or $150 \mathrm{~m}$. Adaptive sampling targeting particular oxygen values (phys- iology and oxycline tows) was also done. At SKQ, 2 sequential day tows (Tows 718 and 719) and 1 night tow (Tow 720), which targeted the 350-650 m depth zone with eight sampling nets for each tow, opportunistically encountered different vertical oxygen profiles, and some species distributions responded to this variability. This tow series is referred to as the "mid-depth comparison". Results from horizontally sequenced tows at specific mesopelagic depths within the OMZ, performed during the R/V Sikuliaq cruise, were previously published (Wishner et al., 2018).

Zooplankton were sampled on the upcast portion of a tow close to noon or midnight, and the hydrographic data from the MOCNESS sensors taken simultaneously with the sampling were used. In a few instances when sensors failed, hydrographic information for some depths was used from the downcast portion of the tow or from a nearby conductivitytemperature-depth (CTD) cast. The MOCNESS was towed at a speed of $\sim 1.5 \mathrm{kt}$ along an oblique path; vertical speeds during the deeper sampling upcast were typically 1 to $3 \mathrm{~m} \mathrm{~min}^{-1}$. Because OMZ zooplankton are sparse, large volumes of water (typically 600 to $>1000 \mathrm{~m}^{3}$ ) were filtered by each net for the deeper samples, and those nets were open for $\sim 20$ min each. The duration of the deeper tows was $\sim 7 \mathrm{~h}$ (most of a day or night, centered around noon or midnight). Shallower tows were shorter in duration, and smaller volumes were filtered for the mixed layer and upper water samples. Details of tows (time and location), depth intervals, and volume filtered for each net are in Table S1 (Wishner et al., 2019) and the BCO-DMO data repository (see the data availability section).

By combining data from multiple tows for a given location to construct a full depth series, we were able to resolve fine-scale vertical distributions within the $\mathrm{OMZ}$ and at its upper and lower boundaries. The process for assembling vertical profiles from multiple tows was described in Wishner et al. (2013) for the 2007 and 2008 cruises; a similar process was used for the other cruises although depth strata varied (Table 1).

\subsection{MOCNESS instrument}

Two versions of the $1 \mathrm{~m}^{2}$ MOCNESS were used. The R/V Seward Johnson and R/V Knorr cruises used the University of Miami's classic MOCNESS with the standard MOCNESS deck unit, software, and sensors, with the oxygen sensor incorporated into the options unit. The R/V Oceanus and R/V Sikuliaq cruises used the upgraded Scripps Institution of Oceanography's MOCNESS in which a Sea-Bird 911CTD with hydrographic sensors and software was physically attached to the MOCNESS frame and its software integrated with the MOCNESS system (Wishner et al., 2018); the bottle-closing CTD feature was transformed into a net bar release controller. The basic net frame and nets, net bar release mechanism, and flow meter were the same in both systems. The recent upgrades provided more stable hydro- 
Table 1. Cruises, stations, tows, and net depth intervals used in copepod abundance graphs. Several tows were often combined to obtain detailed vertical profiles to depth (see Sect. 2.1). D: day; N: night; NS: no sample. Parameters for each tow (dates, times, locations) are in the BCO-DMO data repository, and Table S1 (Wishner et al., 2019) provides depth and abundance data for each net (see data availability section for DOI numbers).

\begin{tabular}{|c|c|c|c|c|c|c|}
\hline $\begin{array}{l}\text { Cruise and } \\
\text { stations }\end{array}$ & $\begin{array}{l}\text { Station } \\
\text { abbrev }\end{array}$ & $\begin{array}{l}\text { Time } \\
(\mathrm{D} / \mathrm{N})\end{array}$ & Tow IDs & $\begin{array}{l}\text { Dates } \\
\text { GMT }\end{array}$ & $\begin{array}{l}\text { Depth } \\
(\mathrm{m})\end{array}$ & $\begin{array}{l}\text { Net intervals } \\
(\mathrm{m})\end{array}$ \\
\hline \multicolumn{7}{|c|}{18 Oct-17 Nov 2007, R/V Seward Johnson (SJ07) } \\
\hline $\begin{array}{l}\text { Tehuantepec } \\
\text { Bowl }\end{array}$ & $\mathrm{TB}$ & $\mathrm{D}$ & 607 & 28 Oct & $0-1200$ & $0-20-80-150-350-550-750-900-1200$ \\
\hline $\begin{array}{l}\text { Costa Rica } \\
\text { Dome }\end{array}$ & CRD & $\mathrm{N}$ & $\begin{array}{l}615,617 \\
619,621\end{array}$ & $8-11$ Nov & $0-1200$ & $\begin{array}{l}0-20-30-40-50-60-80-100-150-200-250-300-350-400-450- \\
500-550-750-800-850-900-950-1000-1100-1200\end{array}$ \\
\hline $\begin{array}{l}\text { Costa Rica } \\
\text { Dome }\end{array}$ & CRD & $\mathrm{D}$ & $\begin{array}{l}616,618 \\
623\end{array}$ & $8-12$ Nov & $0-775$ & $\begin{array}{l}0-20-30-40-50-60-80-100-150-200-250-300-350-400-450- \\
500-550-575-600-625-650-675-700-733-775\end{array}$ \\
\hline \multicolumn{7}{|c|}{8 Dec 2008-6 Jan 2009, R/V Knorr (19502, KN08) } \\
\hline $\begin{array}{l}\text { Tehuantepec } \\
\text { Bowl }\end{array}$ & TB & $\mathrm{D}$ & $\begin{array}{l}626,630, \\
631\end{array}$ & $\begin{array}{l}15,17-18 \\
\text { Dec }\end{array}$ & $0-1000$ & $\begin{array}{l}0-20-30-40-50-60-80-100-150-200-250-300-350-400-450- \\
500-550-700-775-800-825-850-875-900-1000\end{array}$ \\
\hline $\begin{array}{l}\text { Tehuantepec } \\
\text { Bowl }\end{array}$ & $\mathrm{TB}$ & $\mathrm{N}$ & $\begin{array}{l}628,632, \\
633\end{array}$ & $\begin{array}{l}\text { 17, 19-20 } \\
\text { Dec }\end{array}$ & $0-1000$ & $\begin{array}{l}0-20-30-40-50-60-80-100-150-200-250-300-350-400-450- \\
500-550-700-775-800-825-850-875-900-1000\end{array}$ \\
\hline $\begin{array}{l}\text { Costa Rica } \\
\text { Dome }\end{array}$ & CRD & $\mathrm{D}$ & $\begin{array}{l}635,637, \\
640\end{array}$ & $28-30 \mathrm{Dec}$ & $0-1000$ & $\begin{array}{l}0-20-30-40-50-60-80-100-150-200-250-300-350-400-450- \\
500-525-550-575-600-625-650-750-900-1000\end{array}$ \\
\hline $\begin{array}{l}\text { Costa Rica } \\
\text { Dome }\end{array}$ & CRD & $\mathrm{N}$ & $\begin{array}{l}636,638, \\
641\end{array}$ & $\begin{array}{l}29-30 \text { Dec, } \\
1 \text { Jan }\end{array}$ & $0-1000$ & $\begin{array}{l}0-20-30-40-50-60-80-100-150-N S-200-250-300-350-400- \\
450-500-N S-525-550-575-600-625-650-750-900-1000\end{array}$ \\
\hline \multicolumn{7}{|c|}{16 Apr-6 May 2016, R/V Oceanus (OC1604B) } \\
\hline \multirow[t]{4}{*}{ Oceanus } & OC & $\mathrm{N}$ & 707,709 & $26,28 \mathrm{Apr}$ & $0-1000$ & $\begin{array}{l}0-100-150-200-250-300-350-400-450-550-600-650-700- \\
750-800-850-1000\end{array}$ \\
\hline & OC & $\mathrm{D}$ & 708,710 & 26-29 Apr & $0-1000$ & $\begin{array}{l}0-100-150-200-250-300-350-400-450-550-600-650-700- \\
750-800-850-1000\end{array}$ \\
\hline & OC & $\mathrm{D}$ & 711 & $30 \mathrm{Apr}$ & $350-470$ & $\begin{array}{l}468-460-463-384-390-390-367-385-348 \\
\text { (physiology tow) }\end{array}$ \\
\hline & OC & $\mathrm{D}$ & 713 & 2 May & $600-800$ & $600-625-650-675-700-725-750-775-800$ \\
\hline \multicolumn{7}{|c|}{19 Jan-15 Feb 2017, R/V Sikuliaq (SKQ201701S) } \\
\hline \multirow[t]{11}{*}{ Sikuliaq } & SKQ & $\mathrm{N}$ & 716 & $26 \mathrm{Jan}$ & $0-1000$ & $0-100-200-300-400-500-600-700-800-1000$ \\
\hline & SKQ & $\mathrm{D}$ & 718 & $28 \mathrm{Jan}$ & $350-650$ & $\begin{array}{l}350-400-425-450-475-500-550-600-650 \\
\text { (mid-depth comparison) }\end{array}$ \\
\hline & SKQ & $\mathrm{D}$ & 719 & 29 Jan & $350-650$ & $\begin{array}{l}350-400-425-450-475-500-550-600-650 \\
\text { (mid-depth comparison) }\end{array}$ \\
\hline & SKQ & $\mathrm{N}$ & 720 & $31 \mathrm{Jan}$ & $350-650$ & $\begin{array}{l}350-400-425-450-475-500-550-600-650 \\
\text { (mid-depth comparison) }\end{array}$ \\
\hline & SKQ & $\mathrm{N}$ & 721 & $1 \mathrm{Feb}$ & $0-350$ & $0-50-75-100-125-150-200-250-300-350$ \\
\hline & SKQ & $\mathrm{D}$ & 722 & $1 \mathrm{Feb}$ & $0-350$ & $0-50-75-100-125-150-200-250-300-350$ \\
\hline & SKQ & $\mathrm{D}$ & 724 & $5 \mathrm{Feb}$ & 425 & horizontal tow (eight nets) \\
\hline & SKQ & $\mathrm{D}$ & 725 & $5 \mathrm{Feb}$ & $0-1000$ & $0-100-200-300-400-500-600-700-800-1000$ \\
\hline & SKQ & $\mathrm{D}$ & 726 & $7 \mathrm{Feb}$ & 430 & horizontal tow (eight nets) \\
\hline & SKQ & $\mathrm{D}$ & 727 & $8 \mathrm{Feb}$ & $600-825$ & $\begin{array}{l}600-625-650-675-700-725-775-800-825 \\
\text { (Oxycline Tow) }\end{array}$ \\
\hline & SKQ & $\mathrm{D}$ & 728 & 9 Feb & 800 & horizontal tow (eight nets) \\
\hline
\end{tabular}


graphic sensor data and facilitated real-time adaptive sampling with an improved shipboard data and graphical user interface. In the two earlier cruises, the net mesh size was $153 \mu \mathrm{m}$; in the two later cruises it was $222 \mu \mathrm{m}$. Sensors included pressure (depth), temperature, salinity, in situ fluorescence, light transmission, PAR (later cruises), and a TSK flow meter (for volume filtered). The oxygen sensor for all cruises was a Sea-Bird SBE43, calibrated in advance of the cruises.

\subsection{Sample processing, copepod sorting, and abundance data}

At sea, cod ends upon retrieval were placed in buckets with plastic ice packs to maintain cool temperature in the tropical heat. Fresh samples were rinsed with filtered seawater into large $153 \mu \mathrm{m}$ mesh metal sieves and photographed. Most samples from the earlier cruises were then split in a flat-bottomed Motoda splitter. Typically, a half split was preserved in $4 \%$ sodium-borate-buffered formaldehyde in seawater solution for later species identification, while other splits were used for experimental studies, at-sea sizefractionated biomass measurements (first two cruises), photography, and stable isotope analyses. Samples from the later cruises were usually preserved whole without splitting, except for a few individuals that were set aside for live experiments (and recorded at that time).

Onshore processing, including copepod sorting and identification, varied among the cruises because of time and funding constraints. Onshore sorting of copepods occurred months to years after a cruise. The 2007 CRD tows, most of the 2016 OC tows, and most of the 2017 SKQ tows were sorted to substantial species-level and life stage detail, while others (especially some 2007 and 2008 TB tows) were sorted for only a few selected species. For the 2016 and 2017 cruises, only larger copepods were counted after the sample was poured through a $2 \mathrm{~mm}$ sieve in the lab, while copepods of all sizes were counted in the 2007 CRD samples (targeting major groups). Splits of the whole sample were used in most cases, with a target sample size of 100 calanoid copepods. In some instances for SKQ horizontal tows, Stempel pipette aliquots of the small or large size fractions were checked and quantified for particular taxa. About 22000 identified copepods are included in this paper's dataset.

Certain copepod species were consistently identified and visually searched for in most tows, with a focus on the genera Lucicutia and Pleuromamma and the family Eucalanidae. Many other copepod species were identified when present, except for deeper TB samples (below $200 \mathrm{~m}$ ) for which only targeted species were quantified. Some species, especially ones that were rarer, smaller, immature, or difficult to identify, were not always separated and were often lumped into broader categories such as genus, family, or miscellaneous calanoid. Because adult morphological features are typically needed for species confirmation, identi- fication targeted adult calanoid copepods. For some species in which particular younger stages were abundant, easily recognizable, and essential for ecological understanding, those stages were counted separately. This was especially important for the copepod Eucalanus inermis, which had an obvious diapausing layer sometimes associated with OMZ oxyclines. Copepods were identified by an experienced technician (Dawn Outram) based on the literature and websites, especially Razouls et al. (2005), website http://copepodes. obs-banyuls.fr/en (last access: 15 December 2019). Identifications of individuals were done by hand with Nikon and Wild stereomicroscope and compound microscopes, enabling more detailed species and life stage delineation than possible with bulk sample electronic scanning. An upgraded microscope with greater acuity was used for the 2016 and 2017 sample processing, allowing greater species resolution. Other sample components - including size-fractionated biomass; zooplankton stable isotope and body composition; and abundances of other taxa including euphausiids, fish larvae, cephalopods, and foraminifera - are reported elsewhere or are currently under analysis (Birk et al., 2019; Cass et al., 2014; Cass and Daly, 2014, 2015; Maas et al., 2014; Williams et al., 2014; Wishner et al., 2018, 2013).

During the first two cruises, all individuals of the copepod E. inermis were scanned by microscope for the presence of stored oil, an indicator of diapause. They were categorized as containing oil (orange in color in these preserved specimens), clear (no oil), or brownish (no oil but brown in color). A total of 9998 specimens from all nets and tows, separated by life stage from copepodite 3 to adult females and males, were examined. Only a subset of these data is discussed in this paper.

Abundances within each net, usually reported as number of individuals per $(1000 \mathrm{~m})^{3}$, were calculated after accounting for split size and volume filtered (Table S1, Wishner et al., 2019). Abundances in vertical distribution graphs are plotted at the mid-depth of the sampling interval. Water column abundance (reported as number of individuals $\mathrm{m}^{-2}$ for a selected depth range, usually $0-1000 \mathrm{~m}$ ) was calculated by multiplying each sample abundance by the depth range of that sample and then summing those values for the complete sample series over the total selected depth range.

\subsection{Species selection for this paper and depth of maximum abundance}

To clarify critical issues about OMZ effects on zooplankton, we selected a subset of 23 species from the extensive full species list (over 300 species) in order to highlight specific responses to OMZ variability (Table 2 ). We chose these species based on their abundance and frequency of occurrence (presence-absence) in the different locations and cruises and their usefulness as examples to illustrate different types of distributional responses to variability in the shape (and lowest oxygen concentration) of the oxygen profile. In 
Table 2. Copepod species discussed in this paper.

\begin{tabular}{l}
\hline OMZ and oxycline species \\
\hline Disseta palumbii \\
Euaugaptilus magnus \\
Euaugaptilus nodifrons \\
Eucalanus californicus \\
Eucalanus spinifer \\
Gaetanus kruppi \\
Gaetanus pseudolatifrons \\
Heterostylites longicornis/longioperculis \\
Lophothrix frontalis \\
Lucicutia hulsemannae \\
Lucicutia ovalis \\
Metridia brevicauda \\
Metridia princeps \\
Paraeuchaeta californica \\
Scaphocalanus magnus \\
\hline OMZ diapause species \\
\hline Eucalanus inermis \\
\hline Diel vertical migrators into OMZ \\
\hline Pleuromamma abdominalis \\
Pleuromamma johnsoni \\
Pleuromamma quadrungulata \\
\hline Epipelagic and thermocline species \\
\hline Haloptilus longicornis \\
Lucicutia flavicornis \\
Mecynocera clausi \\
Subeucalanus subtenuis \\
\hline
\end{tabular}

a set of graphs, we show day and night vertical distributions of particular species relative to the oxygen profile from each sampling location and time (when that species was present).

The depth of maximum abundance (DMA) was defined as the single net and its depth interval with the highest abundance for a particular species day and night at each station during each cruise, with all tows considered (Table 3 ). The MOCNESS sensor data during the time of collection (upcast) were used to delineate the habitat parameters (oxygen and temperature ranges) at the DMA (Table 3); these are from the particular tow and net listed (DMA tow and net ID in Table 4). Most species also occurred (at lower abundance) over a broader vertical range beyond the single DMA net, as evident in the figures and Table S1 (Wishner et al., 2019). Some species exhibited bimodal distributions. It should be noted that because each net in a MOCNESS tow encompassed a range of depths and consequently a range of hydrographic values, it is unknown where within that range the collected animals were actually located. However, our fine-scale sampling in many cases encompassed very narrow environmental intervals such that we could constrain the OMZ habitat preferences and tolerances (oxygen and temperature ranges) for many species.

\section{Results}

\subsection{Environmental structure}

Hydrographic profiles from MOCNESS sensors are shown in Fig. 2 for each location for both the full sampling range $(0-1000 \mathrm{~m})$ and the upper water column $(0-200 \mathrm{~m})$. We selected one oxygen profile from each site and year to represent that location in the vertical abundance graphs, although abundance profiles were derived from combining multiple day and night tows (see Sect. 2.1 and 2.3). In a few cases, we discuss small-scale distributional variability between sequential tows at the same location, especially the mid-depth comparison series at SKQ. Figure S1 in the Supplement shows all MOCNESS oxygen profiles at each station to provide a sense of oxygen variability among tows at the same location.

The OMZ water column consists of several ecological zones, previously described, each of which has a characteristic hydrographic structure and forms the habitat for a suite of organisms and processes (Wishner et al., 2008, 2013). Zonal boundaries depend on both the shape of the oxygen profile and oxygen concentration, and boundary depths vary by profile. We describe these zones briefly below to introduce terminology and provide a framework for analysis. The mixed layer is the water column above the thermocline with high oxygen and temperature. The upper oxycline (UO), which begins just below the thermocline, has decreasing oxygen with depth and may be abrupt or broad. The OMZ core has the lowest oxygen values stable over a depth range; at these locations $\mathrm{OMZ}$ core oxygen was often $<\sim 1-2 \mu \mathrm{M}$ but was always detectable. The lower oxycline (LO) starts at the inflection point at the base of the OMZ core where oxygen begins to increase with depth. The LO is often characterized by a sharp subsurface peak in zooplankton biomass and abundance and the presence of specific indicator taxa. Oxygen would continue to increase below our sampling range.

The lowest oxygen values in the $\mathrm{OMZ}$ core during these cruises occurred at CRD and TB (values down to $1.0 \mu \mathrm{M}$ ). The mixed layer was very thin at both CRD and TB, with the start of the thermocline at 16-34 $\mathrm{m}$ in different tows and with temperature and oxygen decreasing rapidly below. However, TB in 2007 had a subsurface oxygen intrusion in the upper oxycline zone, so the OMZ core did not begin until about $350 \mathrm{~m}$ and extended to $550 \mathrm{~m}$, similar to the OMZ core extent at CRD that same year. TB in 2008 had the most vertically extensive OMZ core (oxygen values of 1.1-1.5 $\mu \mathrm{M}$ ) extending from depths of 80-700 $\mathrm{m}$, with an abrupt thermocline and almost nonexistent upper oxycline. It was also notable for the occurrence of double subsurface fluorescence peaks, one near the shallow thermocline $(\sim 40 \mathrm{~m})$ as expected and also a deeper peak at $\sim 120 \mathrm{~m}$ within the low-oxygen water of the OMZ core.

The mixed layer extended deeper at the northern stations, OC and SKQ. Fluorescence peaks near the thermocline were deeper ( 80-100 m) at OC and SKQ, compared to the 


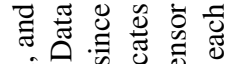
至i 空

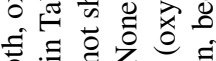
휭

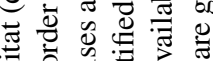

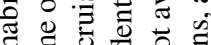
差它

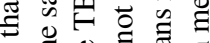

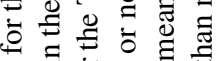

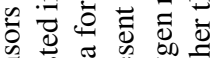

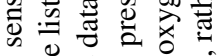

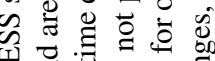

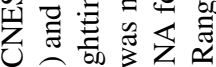

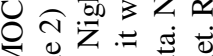

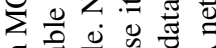

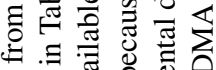

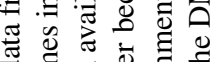

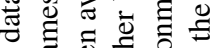

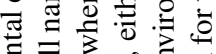

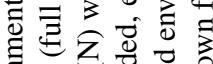

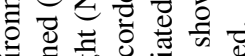

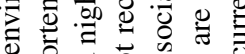

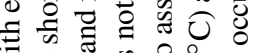

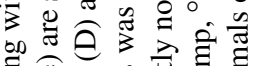

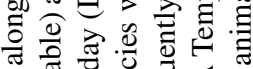
एँ

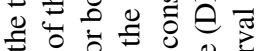

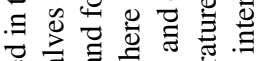

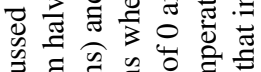

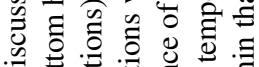

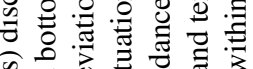
包过

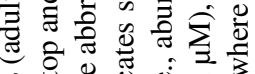

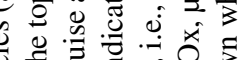
过

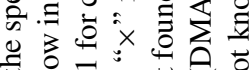
o

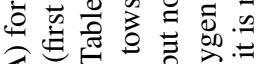
বิ 㱐

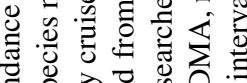

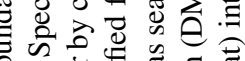

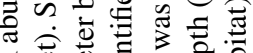

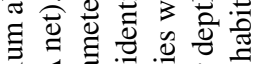

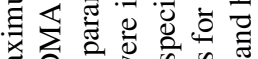

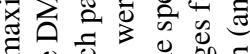

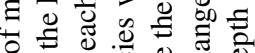

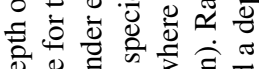

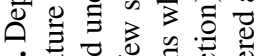

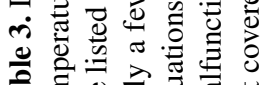

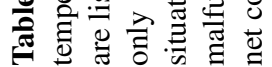

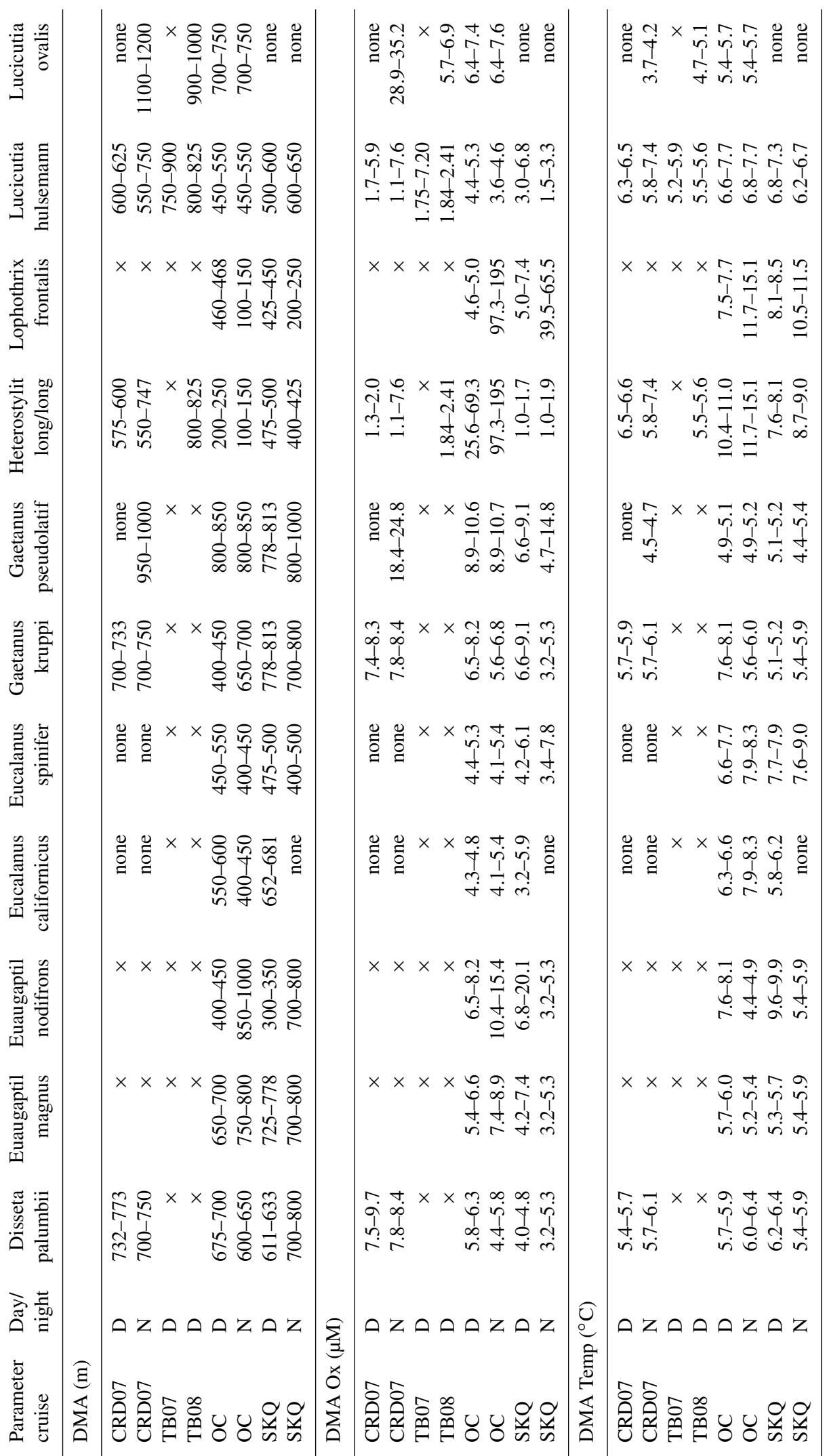

Biogeosciences, 17, 2315-2339, 2020 


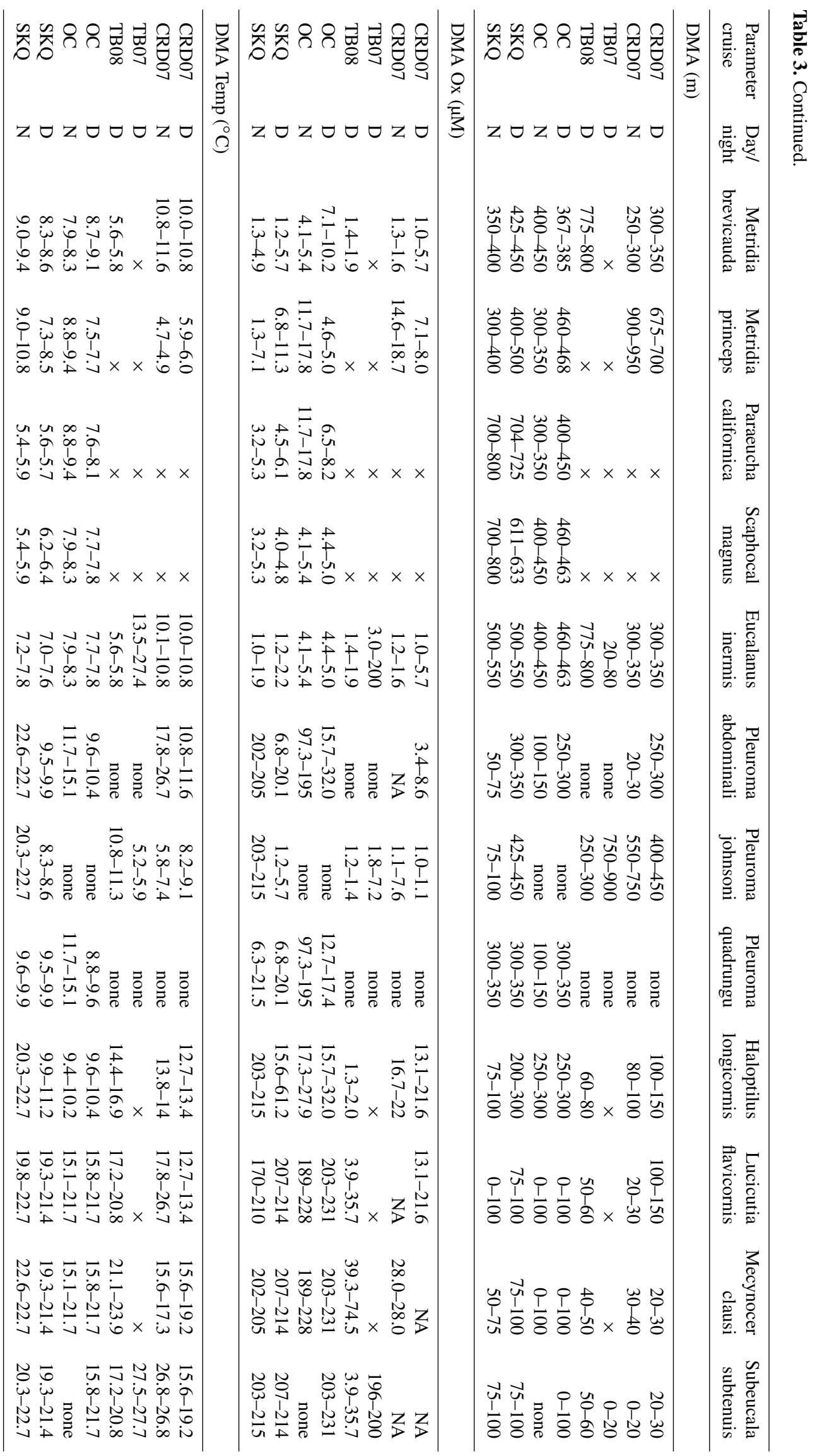




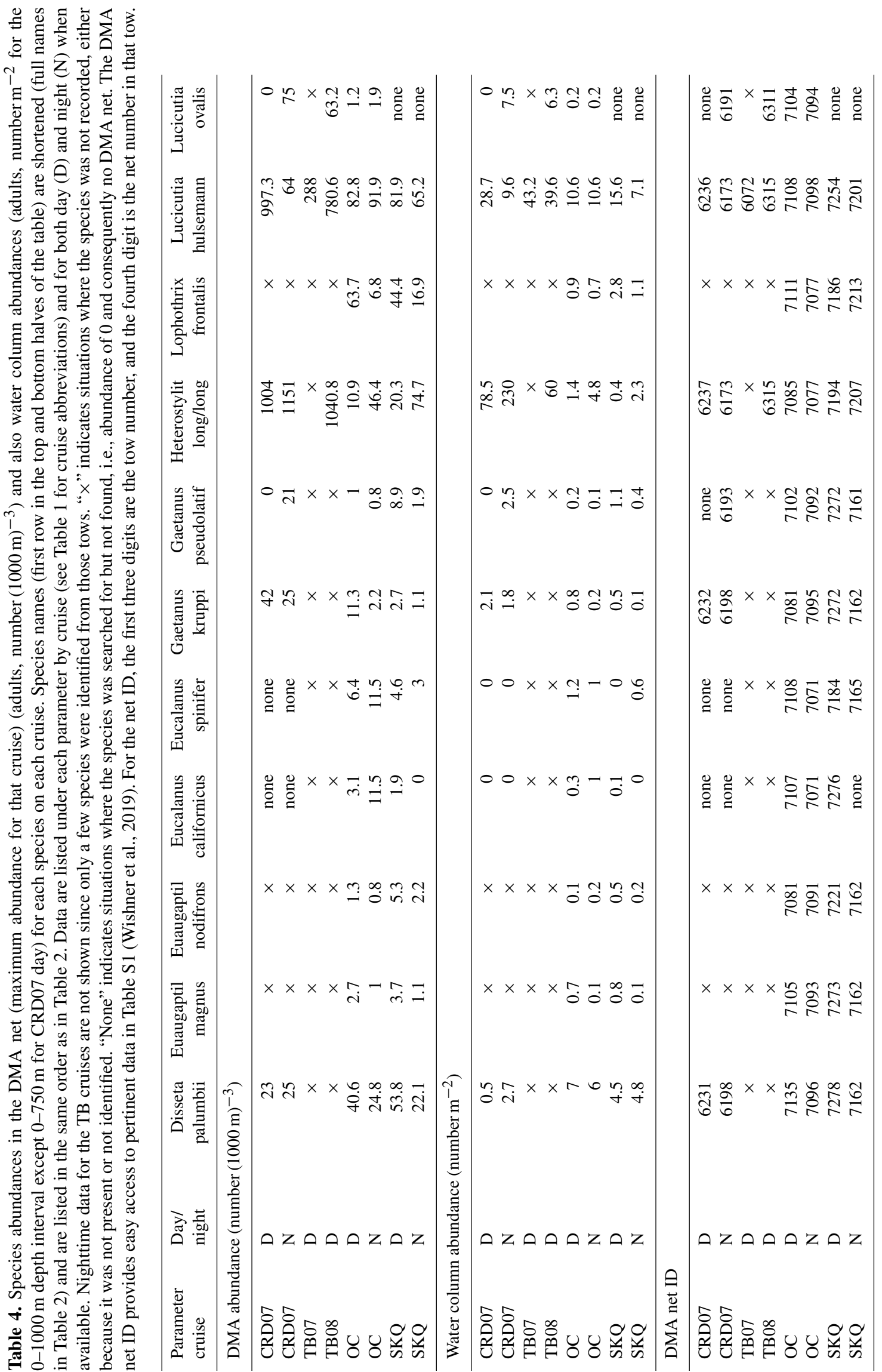




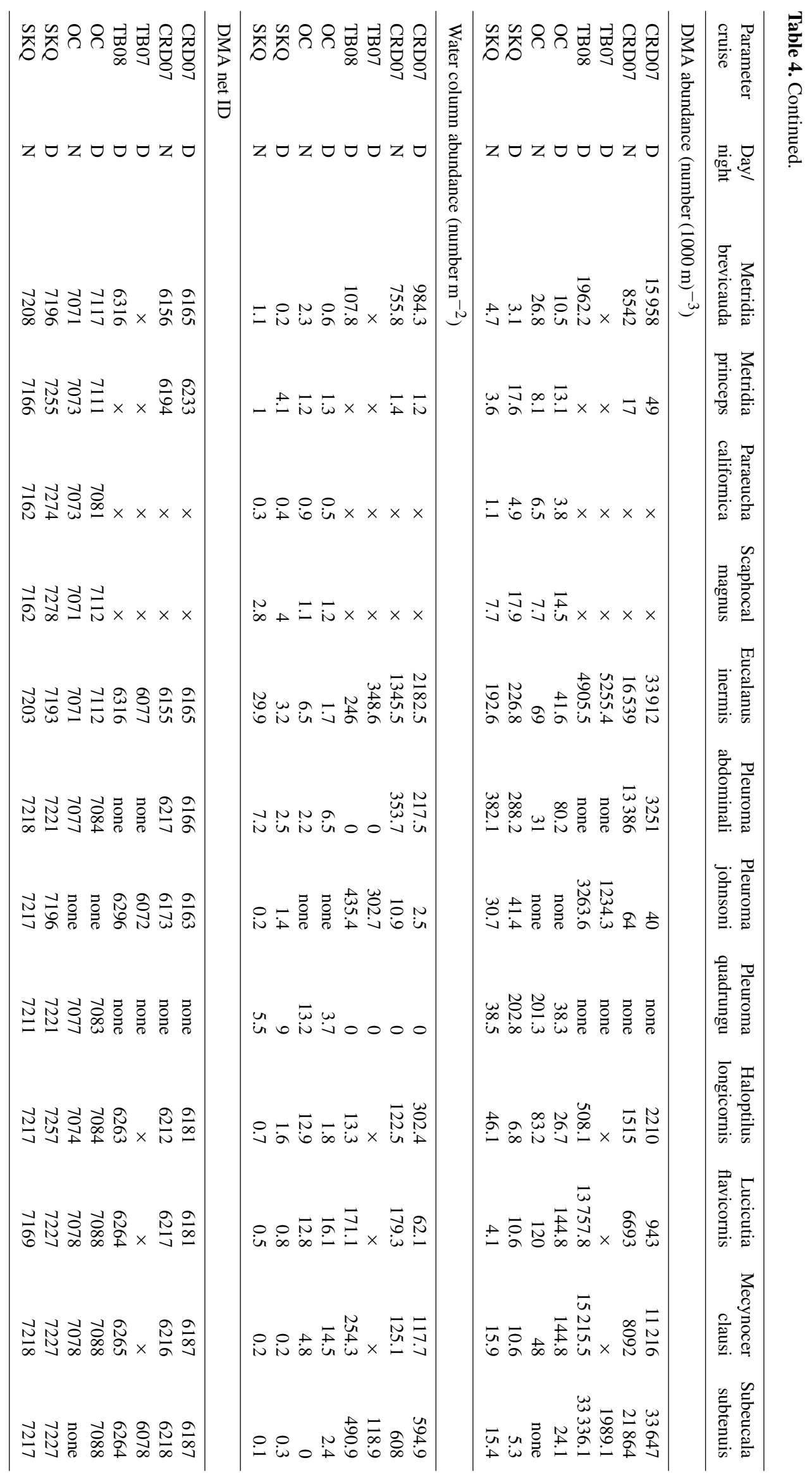



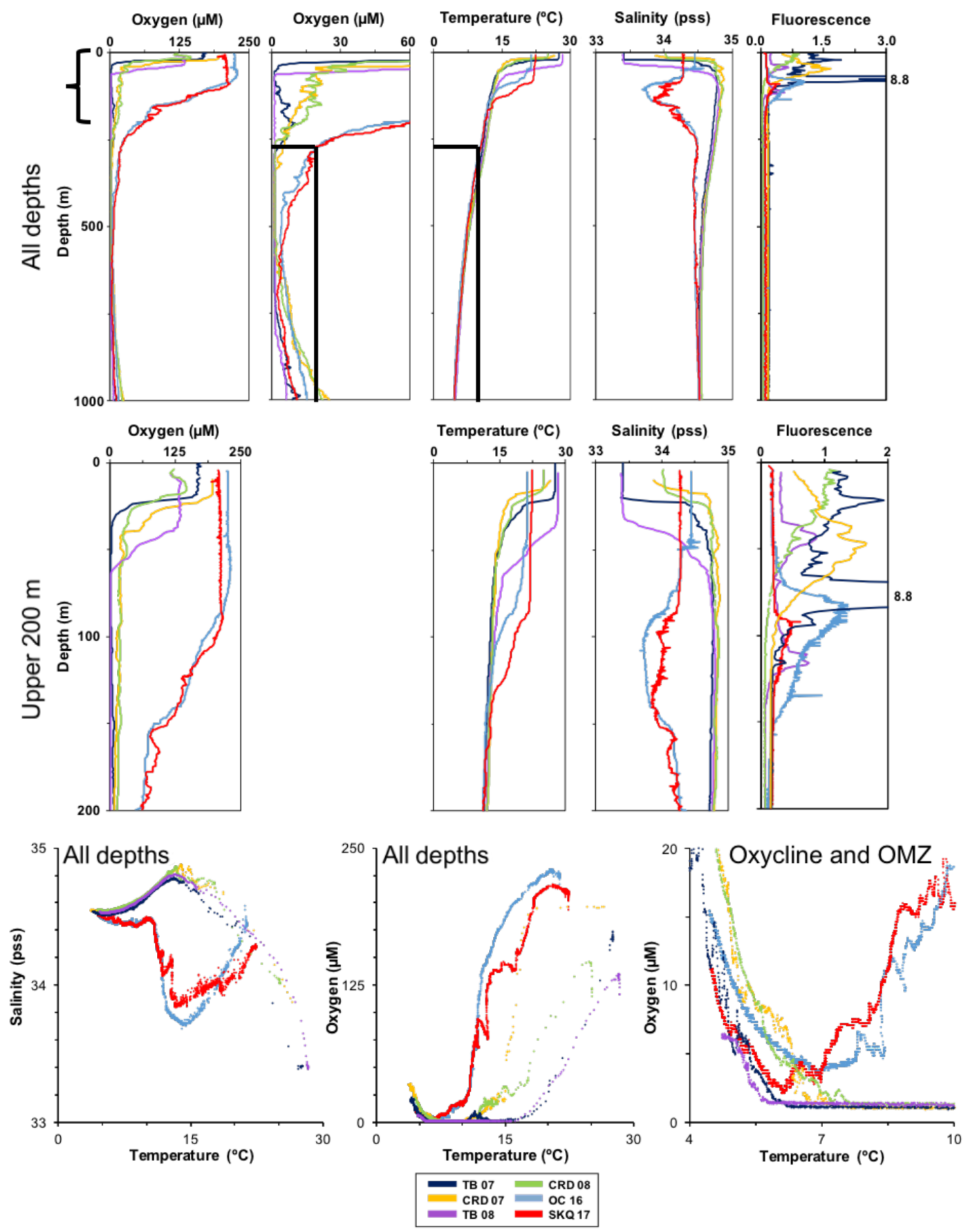

Figure 2. Hydrographic data. Top row: hydrographic profiles for 0-1000 m (noted as "All depths"). Each station (colors) is represented by one profile for each variable; all stations are included for that variable in one graph. Stations are noted by abbreviation and year. Two versions of the oxygen profiles are shown: a full range version $(0-250 \mu \mathrm{M})$ to encompass oxygen from the surface to depth (top left) and a higher-resolution version with a smaller oxygen range $(0-60 \mu \mathrm{M})$ to highlight the OMZ core and oxycline variability between stations (top row, second from left). Second row: similar profiles for the upper water column (noted as "Upper 200 m" and with its depth range indicated by the bracket on the "All depths" plot). Only a single oxygen range is used for this well-oxygenated part of the water column. Bottom row: Temperature-salinity diagram (bottom left) and two temperature-oxygen diagrams, with the first (bottom middle) encompassing the full range of these variables and the second (bottom right) highlighting the smaller temperature and oxygen ranges and variability associated with the OMZ core and oxyclines at the different stations (data range shown by the outlined box in the "All depths" oxygen and temperature plots). 
thermocline-associated peak $(\sim 50 \mathrm{~m})$ at CRD. At OC and SKQ, the oxygen profile was more rounded in shape without a clear-cut extensive OMZ core. The upper oxycline was broad, with relatively high oxygen concentration down to $\sim 450 \mathrm{~m}$. The OMZ core was narrow (only $\sim 25 \mathrm{~m}$ thick, $\sim 525-550 \mathrm{~m}$ at $\mathrm{OC}$ and at more variable depths between 400 and $600 \mathrm{~m}$ in different tows at SKQ). Oxygen values in the core at $\mathrm{OC}$ reached only as low as $3.6 \mu \mathrm{M}$, substantially higher oxygen than at CRD or TB. SKQ had some low oxygen values of $1.0 \mu \mathrm{M}$ for parts of particular net intervals, especially in the mesopelagic horizontal tows during transects through submesoscale features (Wishner et al., 2018).

Temperature decreased with depth below the thermocline and was similar through the mesopelagic at all these stations (Fig. 2). Mixed layer salinity was comparatively low except at the OC and SKQ stations, which were farther north than those of the earlier cruises, and where there was a subsurface salinity minimum $(\sim 80-250 \mathrm{~m})$, likely an influence of the southern extent of the California Current.

Temperature-salinity and temperature-oxygen graphs illustrate the different water masses and metabolic habitats encountered (Fig. 2, bottom row). The high-resolution temperature-oxygen graph (bottom right) highlights the small-scale habitat variability of the OMZ and oxyclines (see also Wishner et al., 2018). In different locations, animals at the same mesopelagic depth (i.e., same temperature) could experience quite different oxygen regimes; animals tracking a specific oxygen concentration might live at different depths (and temperatures).

\subsection{Copepod distributions and responses to oxygen profile variability}

Copepod distributions are presented in a series of graphs and tables described below. Environmental data (ranges for depth, oxygen, and temperature) in the DMA net are shown in Table 3. Abundances (number $(1000 \mathrm{~m})^{-3}$ ) in the single net at the depth of maximum abundance (DMA) for each species day and night, along with day and night water column abundances (number $\mathrm{m}^{-2}$ usually for the $0-1000 \mathrm{~m}$ depth interval) for that species on that cruise, are in Table 4. Abundances of each species in all tows and nets are in Table S1 (Wishner et al., 2019).

\subsubsection{OMZ oxycline and OMZ core species that shift depth and track oxygen}

These were primarily mesopelagic species, most with no diel vertical migration, whose peak abundance was associated with the inflection point at the upper edge (UO) or lower edge (LO) of the OMZ core. These species showed distributional shifts associated with the changing depth of the inflection points and the OMZ core on the different cruises (details below). Peak abundances often occurred abruptly in a very narrow depth interval (a single or only a few sampling nets) and could be several orders of magnitude higher than in adjacent nets.

Lucicutia hulsemannae. This copepod (Markhaseva and Ferrari, 2005), formerly called $L$. grandis, is considered to be an indicator species of the LO (Wishner et al., 2000, 2013). Its peak abundance (Table 4) occurred at the LO inflection point at the base of the OMZ core in the tows with lowest oxygen and most extensive OMZ (Fig. 3, Table 3). Its maximum abundance in a single net (997 individuals $(1000 \mathrm{~m})^{-3}$ ) (Table 4) occurred at 600-625 $\mathrm{m}$ at CRD in 2007, with oxygen in that interval at $1.7-5.9 \mu \mathrm{M}$ and temperature at 6.3$6.5^{\circ} \mathrm{C}$ (Table 3). It was also very abundant at TB in 2008 (maximum of 781 individuals $(1000 \mathrm{~m})^{-3}$ ) (Table 4), but in this case that peak occurred deeper $(800-825 \mathrm{~m})$ and thus at lower temperature $\left(5.5-5.6^{\circ} \mathrm{C}\right)$, just below the extensive OMZ core of lowest oxygen (Table 3). This net sampled a more constrained oxygen range $(1.8-2.4 \mu \mathrm{M})$ confirming that this species can thrive in extremely low oxygen water (Wishner et al., 2018). At OC and SKQ, where oxygen was not as low and where the oxygen profile was more rounded without a clear-cut OMZ core, L. hulsemannae was distributed more broadly throughout the overall OMZ and both oxyclines (Fig. 3), and its water column abundance (7$16 \mathrm{~m}^{-2}$ from $0-1000 \mathrm{~m}$ ) was usually lower (Table 4). Maximum abundances $\left(65-92\right.$ individuals $\left.(1000 \mathrm{~m})^{-3}\right)$ (Table 4) were also substantially less (with one exception) and occurred shallower $(450-550 \mathrm{~m}$ at OC; $500-600$ or $600-650 \mathrm{~m}$ at SKQ) at these northern stations, although temperature at depth was similar to CRD (Table 3). During SKQ in horizontally sequenced tows reported elsewhere, this species also had strong physiological and distributional responses to very small (several $\mu \mathrm{M}$ ) oxygen differences and had higher abundances in lower oxygen (Wishner et al., 2018). In the SKQ mid-depth comparison series, the highest abundances were usually associated with the tow and nets with lower oxygen (Fig. 4). Younger stages, from copepodite 2 to 5 , were recorded, and often abundant, in many of the same nets and depths as the adults. No adults or young stages were found in shallow samples. L. hulsemannae thus appears to be actively growing and developing within this extremely hypoxic part of the OMZ.

A congeneric species, Lucicutia ovalis, occurred in the deeper LO several hundred meters below L. hulsemannae and consequently at lower temperature and higher oxygen levels (Table 3, not graphed). It also shifted depth between locations and was deeper at CRD (1100-1200 m) and TB $(900-1000 \mathrm{~m})$ (stations with a thick OMZ) than at OC (700$750 \mathrm{~m}$ ). It was less abundant than L. hulsemannae and was not found on the SKQ cruise (perhaps due in part to its small size and likely absence from the large size fraction that was sorted).

Disseta palumbii. This widely distributed species in the family Heterorhabdidae (Razouls et al., 2005-2019) was also typical of the LO, but its abundance peaked about $50-100 \mathrm{~m}$ deeper than L. hulsemannae (Fig. 3). Consequently, the oxy- 


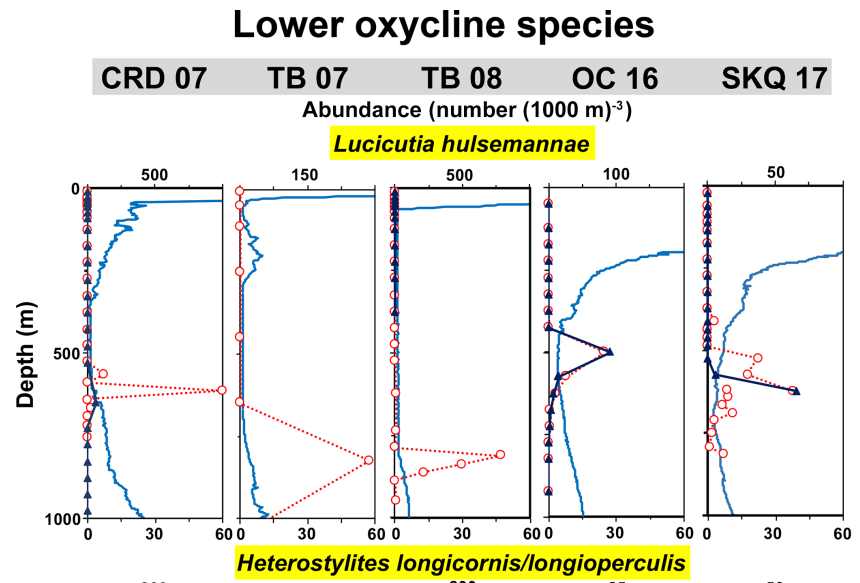

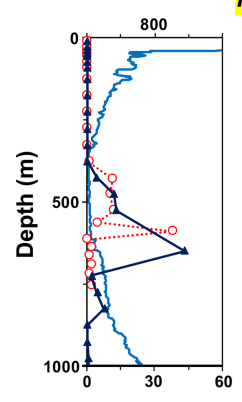
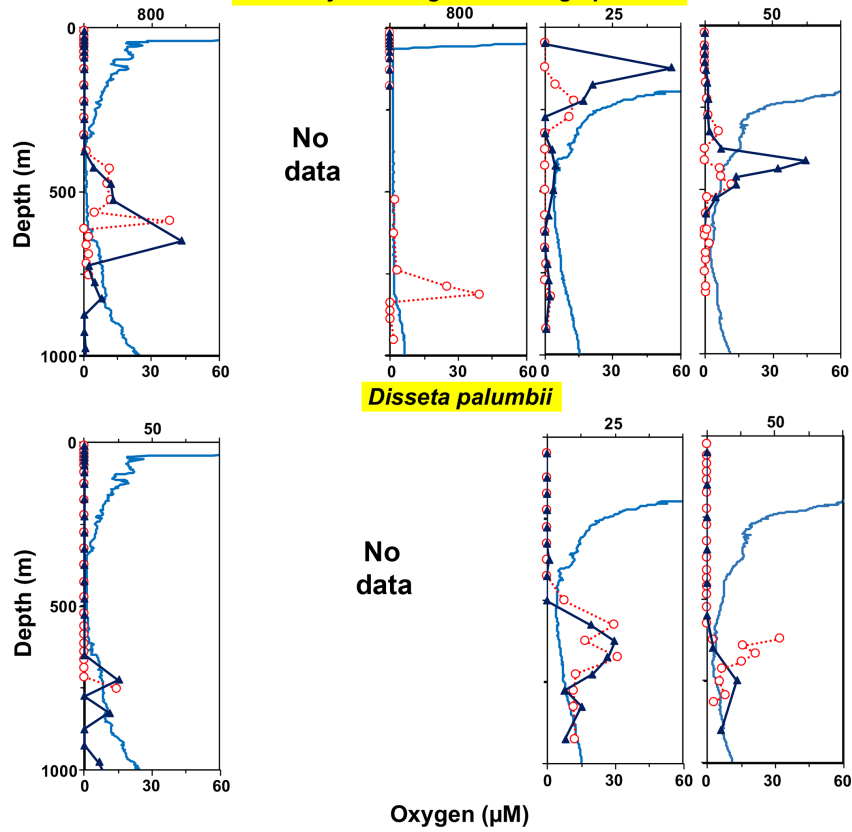

Figure 3. Vertical distributions relative to oxygen: lower oxycline species. Vertical distributions day (red) and night (dark blue) relative to the oxygen profile (light blue) at each station from 0 to $1000 \mathrm{~m}$. Stations are noted at the top (station abbreviation and year), and each column comes from the indicated station. Each row is a different species. Missing boxes are locations and cruises where the species was not recorded. "No data" indicates that the species was either not present or not identified to species in those samples. "Absent" indicates that the species was searched for but not found (abundance $=0)$. Abundances (number $(1000 \mathrm{~m})^{-3}$ ) are for adults (combined females and males) and come from nets and tows listed in Table 1. Abundances are plotted at the mid-depth of the sampling interval. Horizontal abundance axes vary to highlight the peaks. Table S1 (Wishner et al., 2019) provides numerical abundance data for each net.

gen at its DMA was slightly higher and the temperature lower than for L. hulsemannae (Table 3). Its water column abundance and maximum abundance were highest at the stations where $\mathrm{OMZ}$ oxygen was higher, and it was more abundant at OC and SKQ than in earlier cruises (Fig. 3, Table 4). Younger

\section{Mid-depth comparison: three species}

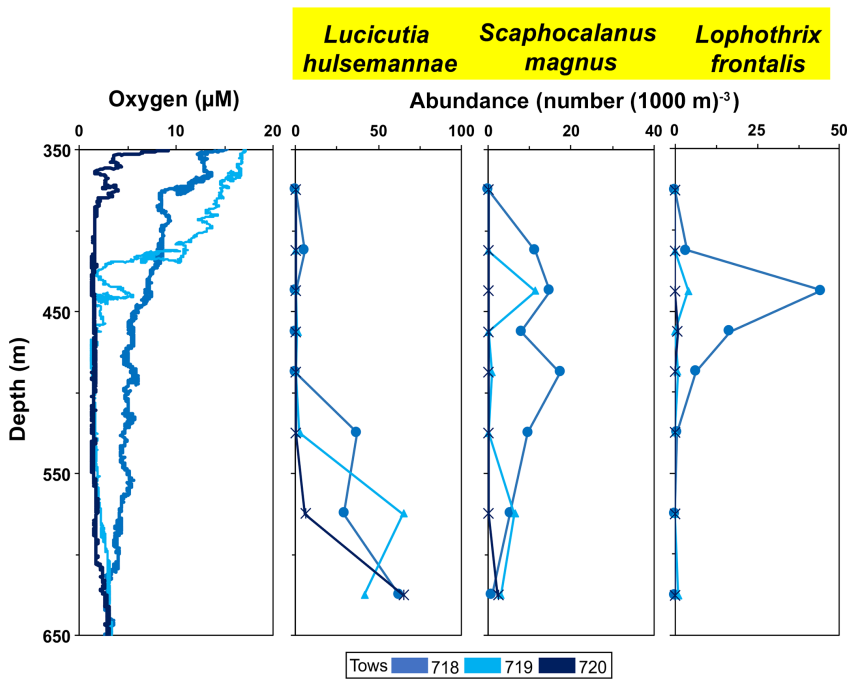

Figure 4. Vertical distributions of three species relative to oxygen for the three sequential tows ( 2 days, 1 night) in the mid-depth comparison series at SKQ 17. Oxygen profiles from each tow (color coded by tow; see legend) are shown in the left graph. Species distributions from each tow are color coded to match the oxygen profile. The depth range for these profiles is $350-650 \mathrm{~m}$. These species responded to the slight variations in oxygen between tows.

stages (copepodites 4 and 5) were present in some cruises at similar depths to adults and were sometimes more abundant than adults.

Another Heterorhabdidae species complex, Heterostylites longicornis/longioperculis, was very abundant from the UO through the OM to the LO and was another characteristic species of this habitat (Fig. 3). It was likely a mixture of two species that are difficult to separate microscopically (Razouls et al., 2005-2019), so it was treated as one entity. In contrast to $D$. palumbii, abundances were highest in the earlier cruises at CRD and TB08 (Table 4), where it co-occurred with $L$. hulsemannae at the LO in very low oxygen. At OC and SKQ where it was less abundant, it occurred primarily in the UO and shallower than L. hulsemannae and D. palumbii. Oxygen values in its habitat at SKQ were similar to the low values of earlier cruises, but in OC its shallower peaks (100-250 m) were at higher oxygen (Table 3). Younger stages occurred at many of the same depths.

Two Aetideidae species, Gaetanus kruppi and Gaetanus pseudolatifrons, and two Augaptilidae species, Euaugaptilus magnus and Euaugaptilus nodifrons, also demonstrated distributional separation between congeners within the LO zone (Fig. 5). G. kruppi occurred shallower than G. pseudolatifrons and usually at lower oxygen and higher temperature (Table 3) because it was closer to the LO inflection point. Both were most abundant at CRD. E. magnus was clearly a LO species, while $E$. nodifrons had a distribution pattern 
split between the UO and LO. These latter two species were identified only from the later cruises.

Several other species, including Metridia brevicauda, Metridia princeps, and Paraeuchaeta californica, also showed a split distribution pattern with peaks of adults usually at both the UO and LO sides of the OMZ core but almost no specimens in the OMZ core itself or in shallow water (Figs. 6, 7). The predominant peak for $M$. brevicauda adults (Fig. 6) was typically in the UO, while the predominant peak for $P$. californica, $M$. princeps, and $E$. nodifrons could be either in the LO or UO (Fig. 7). P. californica and E. nodifrons in the LO occurred deeper and at higher oxygen than the LO secondary peak of M. brevicauda. The LO peak (at 675-700 m) for M. princeps was especially clear-cut at CRD (Table 3) since this species was not present shallower there; however, its highest total water column abundance was at SKQ (Table 4) where it occurred over a broader depth range at both the UO and LO.

Oxygen where $M$. brevicauda was most abundant was 1.0 $5.7 \mu \mathrm{M}$ with a temperature of $10.0-10.8^{\circ} \mathrm{C}$ (Table 3) in the UO of CRD in 2007 (300-350 m, maximum adult abundance (Table 4) in this net of $\left.15958(1000 \mathrm{~m})^{-3}\right)$, indicating the ability of this species to thrive at very low oxygen (similar to L. hulsemannae) but at somewhat higher temperature. Younger smaller life history stages of $M$. brevicauda were quantified in the CRD and TB08 cruises (counted only from 0 to $200 \mathrm{~m}$ and from 550 to $1000 \mathrm{~m}$ in TB08) (Fig. 6), but not in later cruises, when only the large copepod size fraction $(>2 \mathrm{~mm}$ ) was sorted (and small taxa like M. brevicauda may have been underrepresented). Younger stages (copepodites 2-5) occurred at similar depths as adults, while the youngest stage (copepodite 1) was very abundant (up to $23589(1000 \mathrm{~m})^{-3}$ at night) in TB08, primarily in the lower mixed layer (50-100 m). This life history distribution pattern suggested active reproduction at depth, with ontogenetic migration of the youngest stages up into the well-oxygenated warmer mixed layer at some times.

The Scolecitrichidae copepods Lophothrix frontalis and Scaphocalanus magnus were common UO components during the OC and SKQ cruises (not differentiated during earlier cruises), with possible DVM within the UO (Fig. 7). Peak daytime abundance of $L$. frontalis was located at $425-$ $468 \mathrm{~m}$ (oxygen $4.6-7.4 \mu \mathrm{M}$ ), while at night it was at 100-150 or $200-250 \mathrm{~m}$ where oxygen was much higher (Table 3 ). $S$. magnus occurred somewhat deeper (extending from the UO into the OMZ core) and its possible DVM was deeper. Both species also had higher abundances in the higher-oxygen profile of the SKQ mid-depth comparison series (Fig. 4).

\subsubsection{Eucalanus inermis, a copepod that diapauses in the OMZ}

The Eucalanidae copepod E. inermis was especially abundant at CRD and TB where it formed concentrated diapausing layers at the $\mathrm{UO}$ and $\mathrm{LO}$ inflection points (Fig. 8). These were considered diapausing layers because of their life stage composition and the presence of stored oil in many individuals. Stored oil, an indicator of diapause, was visibly apparent as an orange colored material inside many preserved copepods during the first two cruises. Individuals from the diapausing layer that had no obvious stored oil were either brownish or clear in preserved samples. From the total of 9998 E. inermis individuals examined microscopically for oil (all tows and nets on these two cruises), there were 334 adult females from the four DMA nets listed in Table 4 (plus two additional DMA nets, ID numbers 6371 and 6368, from tows at CRD in 2008 not included in Table 4). From $67 \%$ to $93 \%$ of adult female E. inermis in the diapausing layers (DMA nets) during these six tows contained stored oil (total of 269 individuals), as did high proportions of the older immature males (copepodites 4 and 5) also present there. Oil presence was not quantified on the later cruises, but actively swimming specimens from near-surface samples examined live at sea were transparent, with some, but not all, having some transparent stored oil.

Multiple layers (near surface, UO, LO) with different life stage composition and relative abundances occurred at both locations during the first two cruises (Fig. 8). Adult diapausing copepods were primarily females, but large concentrations of copepodite 4 and 5 males and a few adult males, as well as some younger stages, occurred in these same samples. Locations of the diapausing animals were the UO and LO layers, while young stages, as well as some presumably nondiapausing adults, occurred near the surface. The peak abundance of diapausing adults $\left(33912(1000 \mathrm{~m})^{-3}\right)$ (Table 4) was located in a layer at $300-350 \mathrm{~m}$ (UO) during CRD in 2007 (Table 3), while at CRD in 2008 the peak abundance $\left(19242(1000 \mathrm{~m})^{-3}\right)$ (Table 4) was at the LO at 500$550 \mathrm{~m}$ (Table 3). At TB in 2007 the peak adult abundance occurred at the UO (20-80 m), whereas the next year at TB the maximum adult abundance was at the $\mathrm{LO}$ at $775-800 \mathrm{~m}$ (Table 3). At the LO, when the diapausing layer was fortuitously sampled as an entity in a single net, it occurred as a monospecific aggregation located just above the more diverse LO community (e.g., L. hulsemannae and associates), as noted earlier (Wishner et al., 2013). During 2008 at TB, there was also a very high concentration of copepodite 1 and 2 stages (total of $211894(1000 \mathrm{~m})^{-3}$ ) at $60-80 \mathrm{~m}$ at the $\mathrm{UO}$, indicating that reproduction and development had occurred recently (Fig. 8). Similar near-surface layers of mixed life stages, including many immature specimens, were also found at CRD in both years. During the last two cruises, abundances at those more northerly stations were substantially lower (but still included immature life history stages) and were not as sharply layered, occurring within the broad UO (400-550 m). There was no concentrated layer of diapausing animals on these later cruises. No DVM was evident for any cruise.

$E$ inermis diapausing layers (Table 4) were located at extremely low oxygen, 1.0-5.7 $\mu \mathrm{M}$ (except for the shallow 


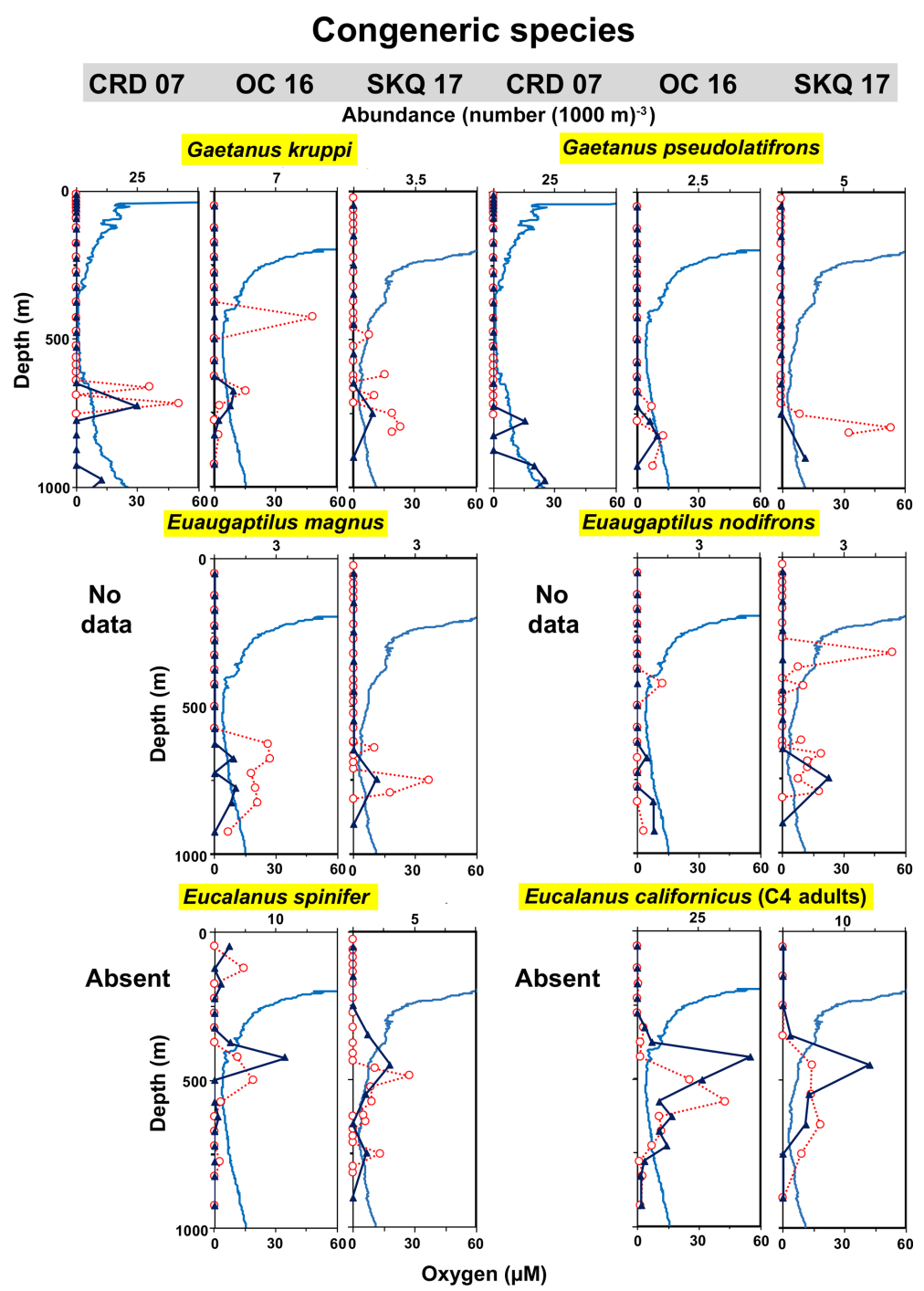

Figure 5. Vertical distributions relative to oxygen: congeneric species from three genera. Each row shows two species (adults) from a particular genus at the same stations (listed at the top and repeated for each half of the figure). Each row is a different genus. See Fig. 3 caption for more explanation.

layer at TB in 2008 where the net probably sampled across zones) (Table 3). These layers were at the edges of the OMZ core but usually not at the lowest oxygen of the OMZ. The large percentage of animals with stored oil in these layers and the sharpness of layer boundaries were strong indicators that this species undergoes its diapause in a precisely defined zone of extremely low oxygen. Our sampling did not address seasonal cycles at particular locations, so we do not know the temporal progression of reproduction and development or how long diapause layers persisted at depth in low oxygen. The brownish or clear specimens may have been animals that had depleted their oil reserves.

Other common copepod species from the family $\mathrm{Eu}-$ calanidae observed during the cruises did not have the obvious diapause behavior of E. inermis. Eucalanus californi- cus and Eucalanus spinifer were moderately abundant farther north during the latter two cruises (not found at CRD and not separately identified at TB) (Fig. 5); they are common in the California Current and subtropics respectively (Goetze, 2003; Goetze and Ohman, 2010). They occurred primarily within the broad UO, with $E$. californicus being slightly deeper and also having many copepodite stages 4 and 5. These species occurred at somewhat higher oxygen than the E. inermis diapausing animals (Table 3).

\subsubsection{Diel vertical migrators and $\mathrm{OMZ}$ intensity}

Copepod species in the genus Pleuromamma (family Metridinidae) are well known as strong diel vertical migrators, including species that descend to mesopelagic depths during the day in the ETNP (Haury, 1988; Hirai et al., 2015; Ra- 
Split distribution: Metridia brevicauda

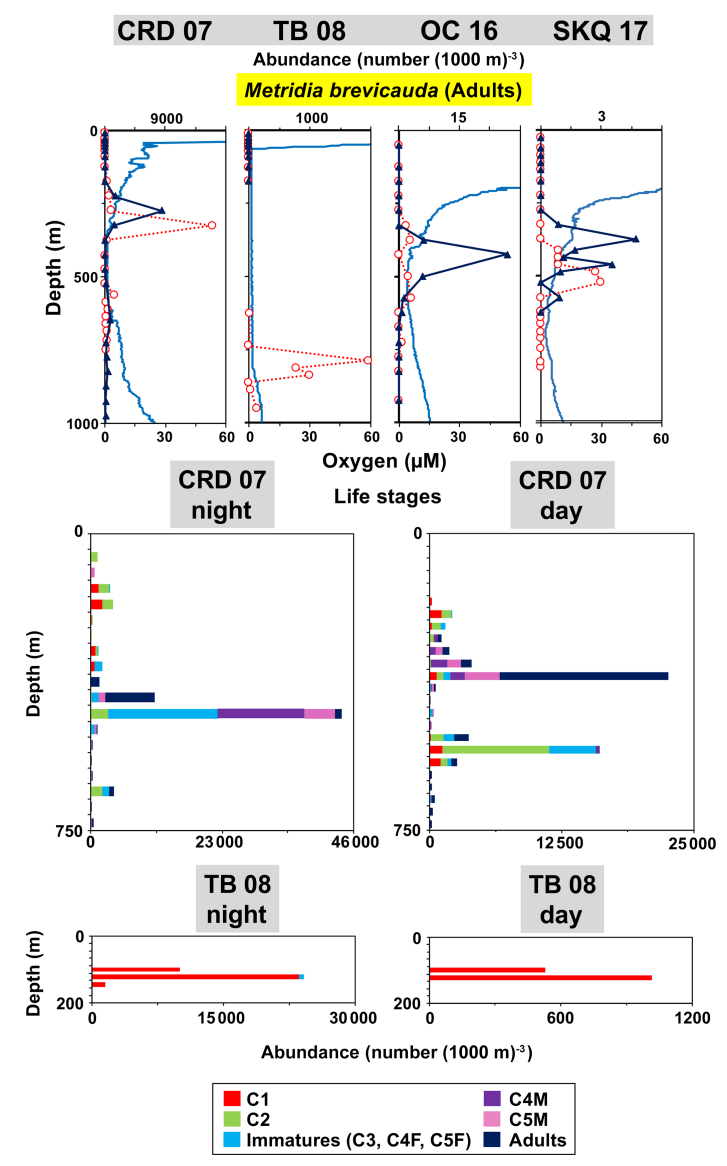

Figure 6. Vertical distributions relative to oxygen for Metridia brevicauda (adults) at each station (top row). Second and third rows: life history stage distributions (color-coded bar graphs) are shown for CRD in 2007 night and day (to $750 \mathrm{~m}$, the deepest depth with both night and day abundance data) and for TB in 2008 for the upper water column (0-200 m, the only depth range with life history stage counts for that cruise) night and day. Abundance axes vary. Bars are plotted by sample order with increasing depth. See the vertical profiles (top row) and Tables 1 and S1 (Wishner et al., 2019) for depth ranges for each net and Table 3 for the DMA. See Fig. 3 caption for more explanation of the vertical profiles.

zouls et al., 2005). Three of these species provided insight into varying strategies in response to differences in OMZ and mixed layer vertical extent and differences in oxygen values among cruises (Fig. 9). We expected that their daytime depth would be most affected by OMZ variability as they coped with different conditions during their diel transit. However, for Pleuromamma abdominalis and Pleuromamma quadrungulata, it was the nighttime depth that changed with the shape of the oxygen profile, while the daytime depth remained similar across cruises for each species (Table 3). For example, for $P$. abdominalis, its nighttime depth was 20 $30 \mathrm{~m}$ at CRD in 2007 in the high-oxygen mixed layer above the sharp thermocline and low oxygen below but $100-150 \mathrm{~m}$

\section{Upper oxycline and split distribution species}

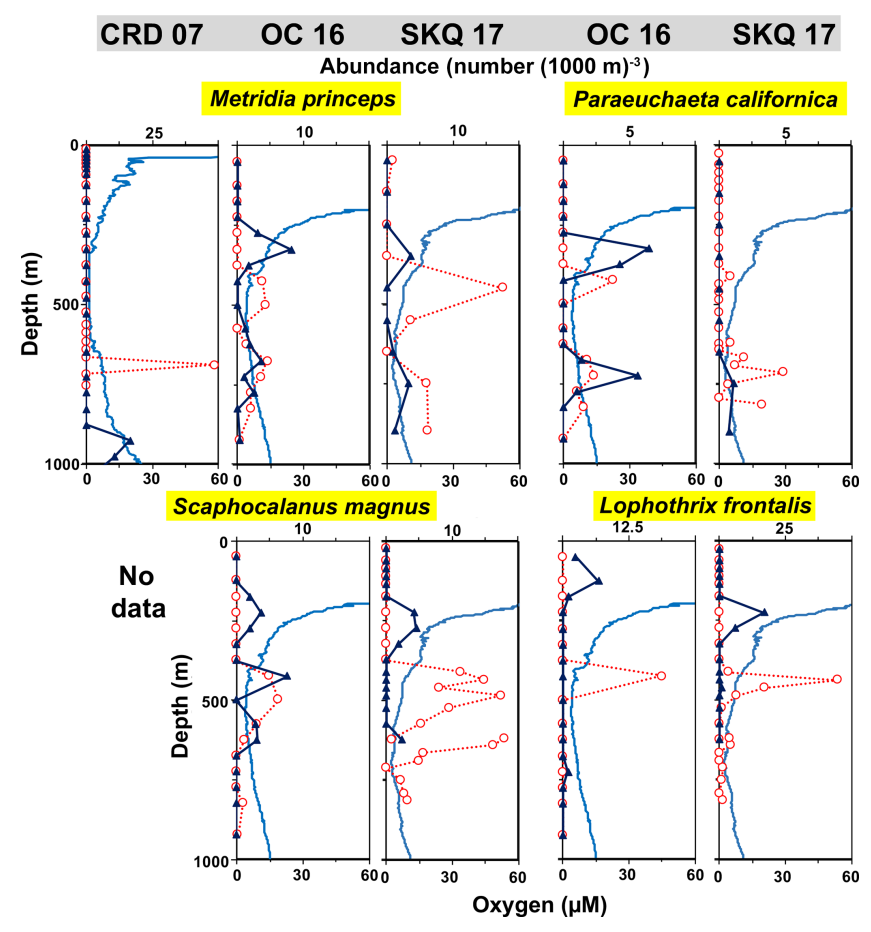

Figure 7. Vertical distributions relative to oxygen: upper oxycline species and those with split oxycline distributions. Two species are shown in each row with stations repeated for each half. See Fig. 3 caption for more explanation.

at OC in 2016 and 50-75 $\mathrm{m}$ at SKQ in 2017 where the mixed layer was broader and higher oxygen extended deeper. Daytime depth was 250-350 $\mathrm{m}$ at all these stations in the UO just above the OMZ core.

Pleuromamma johnsoni (Ferrari and Saltzman, 1998) tended to occur deeper during the day than the other species (400-450 $\mathrm{m}$ at CRD in 2007 and SKQ in 2017) and had some day and night layers associated with the LO below the OMZ core (Fig. 9). At TB in 2008, with its vertically extensive OMZ, abundant daytime layers of $P$. johnsoni occurred at both $250-300 \mathrm{~m}$ in the OMZ core (oxygen 1.2 $1.4 \mu \mathrm{M}$, temperature $10.8-11.3{ }^{\circ} \mathrm{C}$ ) (Table 3 ) and $850-875 \mathrm{~m}$ at the LO inflection point (oxygen $2.5-4.3 \mu \mathrm{M}$, temperature $5.2-5.4^{\circ} \mathrm{C}$ ). There was also an especially abundant nighttime layer of $P$. johnsoni (20059 individuals $(1000 \mathrm{~m})^{-3}$ ) at the thermocline (Fig. 9), where oxygen and temperature were higher $(50-60 \mathrm{~m}$, oxygen $21.8-82.6 \mu \mathrm{M}$, temperature $19.7-$ $\left.24.2^{\circ} \mathrm{C}\right)$.

There were also clear-cut geographic differences in presence-absence and abundance among these species (Fig. 9, Table 4), with $P$. abdominalis most abundant at CRD in 2007 and $P$. quadrungulata most abundant at OC in 2016 and SKQ in 2017 but absent at CRD in 2007. P. johnsoni was most abundant at TB but absent at OC in 2016, whereas the other two Pleuromamma species were absent at TB in both 
Eucalanus inermis: a diapausing species
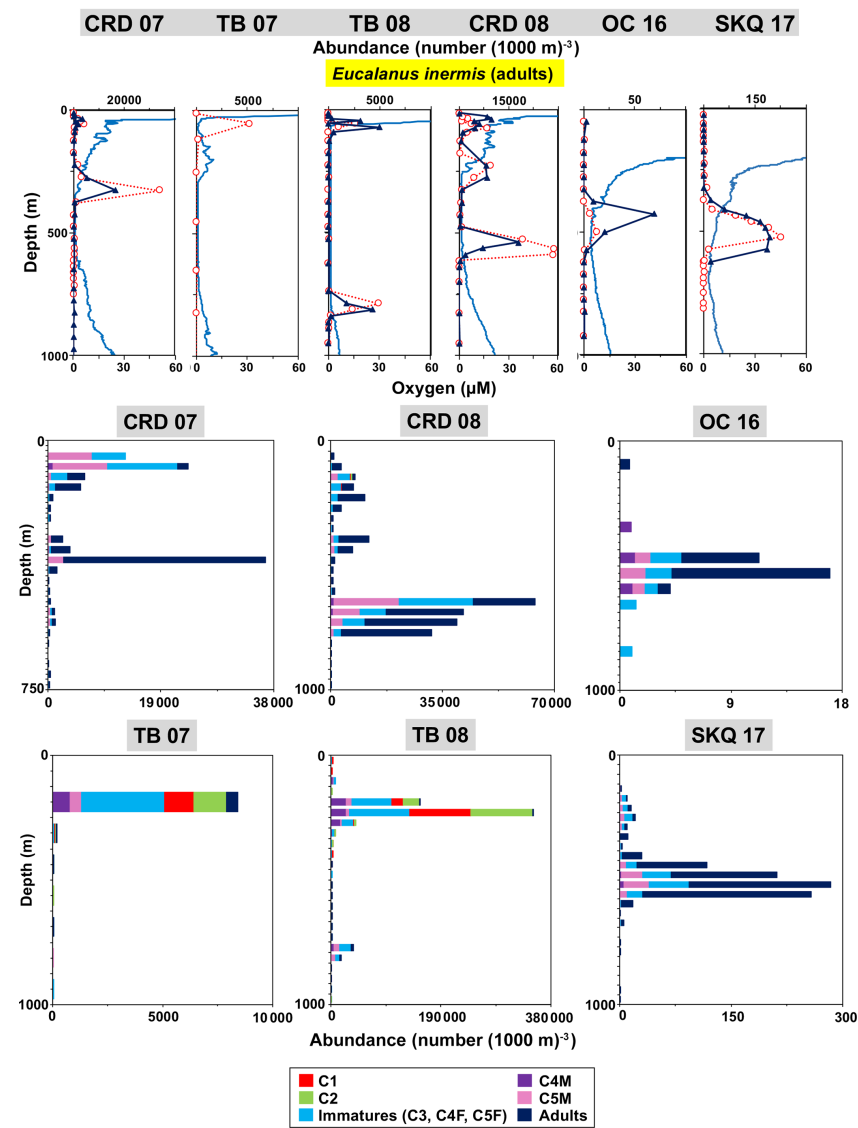

Figure 8. Vertical distributions relative to oxygen for Eucalanus inermis adults day and night at each station (top row), and daytime life history stage distributions (color-coded bar graphs) at each of these stations (two bottom rows). Abundance axes vary. Bars are plotted by sample order with increasing depth. At CRD in 2007, daytime data extended only to $750 \mathrm{~m}$. See the vertical profiles (top row) and Tables 1 and S1 (Wishner et al., 2019) for depth ranges for each net and Table 3 for the DMA. See Fig. 3 caption for more explanation of the vertical profiles.

years (except for one juvenile specimen of $P$. abdominalis). Pleuromamma species were specifically targeted for identification at all stations and nets, so these presence-absence comparisons are strongly supported. Whether these patterns resulted from distinct environmental preferences associated with habitat availability (oxygen and temperature combinations) or from other temporal and spatial changes or ecological factors cannot be resolved with our sampling.

\subsubsection{Epipelagic habitat compression and mixed layer species responses}

Four abundant species that occurred primarily in the warm well-oxygenated mixed layer or near the thermocline were used to examine the aerobic habitat compression hypothesis by comparing copepod abundances from cruises with sub-

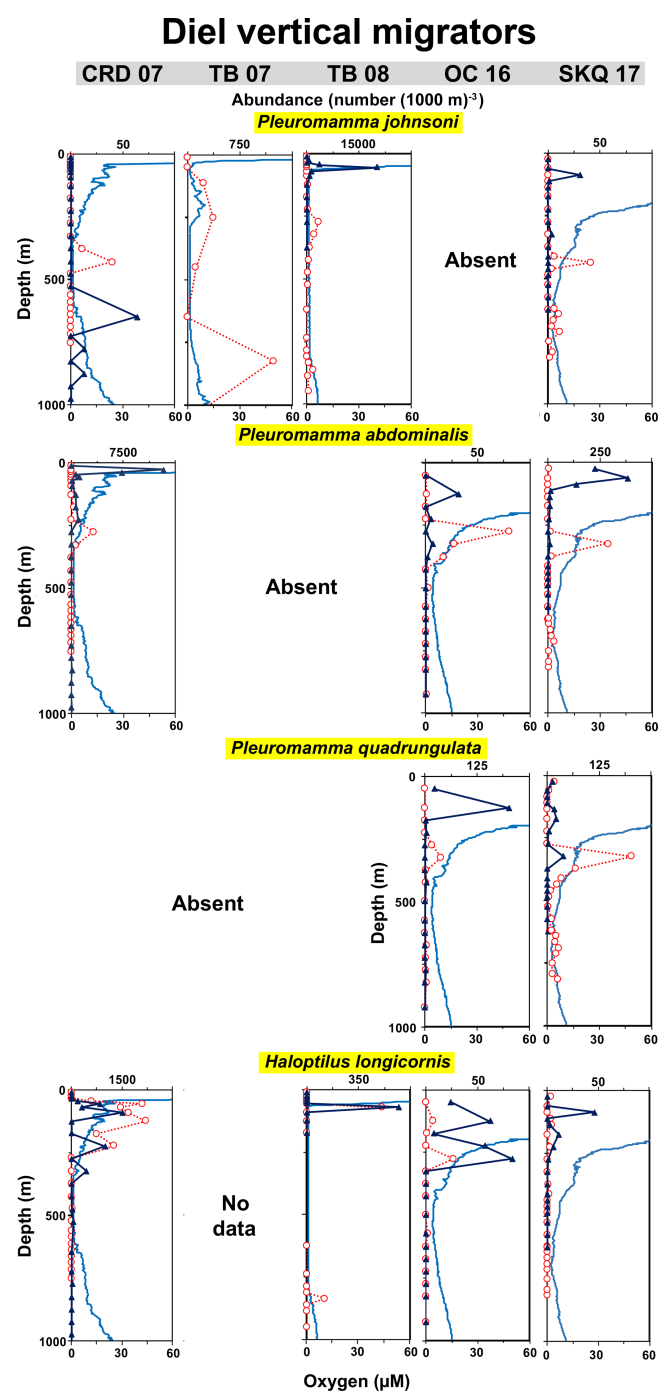

Figure 9. Vertical distributions relative to oxygen: diel vertical migrators. Each row is a different species. For the Pleuromamma species, which were searched for and identified in all tows, missing figures represent locations with zero abundances.

stantial difference in the shape of oxygen profiles. The first two cruises had a narrower aerobic mixed layer habitat with an abrupt transition to the OMZ core, while the last two cruises had a broader aerobic mixed layer and more gradual UO. There were several complications associated with choosing representative epipelagic taxa. Many upper water column tropical copepods were small or hard to identify (i.e., Clausocalanus spp.) or occurred primarily as immature stages; these were not a focus of this OMZ project, and many were not identified to species. During some cruises, the mixed layer was sampled only as a single net interval and not subdivided into multiple strata, so small-scale distributional differences there were not defined. Also, these four species, generally smaller in size than the deeper living copepods discussed earlier, may have been relatively undersampled dur- 

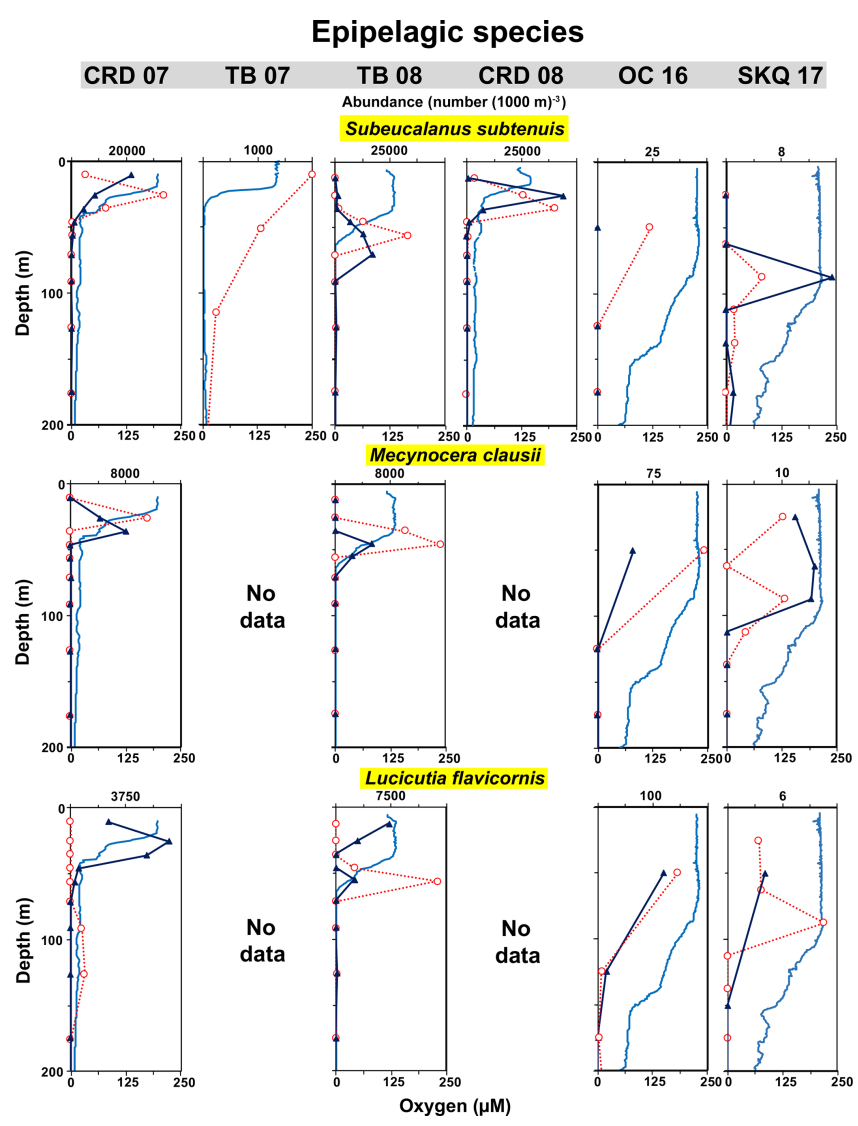

Figure 10. Vertical distributions relative to oxygen: epipelagic species. Each row is a different species. The depth axis for these graphs is $0-200 \mathrm{~m}$. The uppermost point in the graphs includes the sampling interval that extends to the sea surface (plotted at the middepth of the interval). See Fig. 3 caption for more explanation.

ing the later cruises when a slightly larger mesh size was used and only the $>2 \mathrm{~mm}$ size fraction sorted; however, this should not affect within-cruise distributional patterns.

The Eucalanidae copepod Subeucalanus subtenuis, the Paracalanidae copepod Mecynocera clausi, and the Lucicutiidae copepod Lucicutia flavicornis were most abundant shallower in the thermocline at the first two stations (20$30 \mathrm{~m}$ at CRD in 2007, 40-60 $\mathrm{m}$ at TB in 2008) but occurred deeper and in lower abundance within the broader mixed layer (usually 75-100 m) on the later cruises (Fig. 10). Maximum abundances (Table 4) reached $33647(1000 \mathrm{~m})^{-3}(S$. subtenuis during CRD in 2007, 20-30 m, Table 3). There was no clear signal of DVM for these species, although our sampling cannot rule out small-scale shifts within the mixed layer. For these abundant epipelagic copepods, the vertical range contraction observed in distributions in the two earlier cruises compared to the later ones was likely a response to habitat compression of the aerobic mixed layer.

Another abundant copepod, the Heterorhabdidae Haloptilus longicornis, occurred at the base of the mixed layer in the first two cruises (100-150 m at CRD in 2007 and 60-
$80 \mathrm{~m}$ at TB in 2008 during the day) but substantially deeper within the UO (200-300 $\mathrm{m}$ during the day) in the latter two cruises (Fig. 9). Because of the different shapes of the oxygen profiles, oxygen at these very different daytime depths was similar and moderate (13.1-61.2 $\mu \mathrm{M})$, except at TB in 2008, which had lower oxygen. However, temperature was about $3{ }^{\circ} \mathrm{C}$ lower at the deeper daytime depths in the latter cruises compared to the shallower earlier ones (Table 3). Additionally, H. longicornis exhibited a short DVM up to $75-100 \mathrm{~m}$ at night at two of the stations.

\section{Discussion}

\subsection{Overview}

The unique feature of our work is the effort to document precise habitat conditions pertinent to metabolic requirements (oxygen and temperature) at depths where particular species are most abundant, as well as how the shapes of their vertical abundance profiles are modified in concert with the changing vertical profiles of oxygen in these extreme OMZ habitats.

Although the ETNP copepod fauna and, in some cases, distributional relationships to oxygen have been studied previously in numerous locations and programs (FernándezÁlamo and Färber-Lorda, 2006), the sampling schemes, technology, and scientific foci differed from ours. Chen (1986) analyzed vertical distributions for both individual copepod taxa and large multispecies samples, collected with openingclosing bongo nets, at stations along a transect from Baja California to the Equator during the Krill Expedition. Copepod vertical distributions in the Costa Rica Dome, long known as a productive feature important to fisheries (Fiedler, 2002; Landry et al., 2016), have been reported (Décima et al., 2016; Fiedler, 2002; Jackson and Smith, 2016; Landry et al., 2016; Sameoto, 1986; Vinogradov et al., 1991; Wishner et al., 2013). Copepod vertical distributions from MOCNESS tows near the Volcano 7 seamount in the ETNP $\left(13^{\circ} \mathrm{N}\right.$, $102^{\circ} \mathrm{W}$ ) were described by Saltzman and Wishner (1997). Many studies also analyzed vertical distributions of some of these species in adjacent subtropical regions, including the central north Pacific (Ambler and Miller, 1987; Landry et al., 2001; McGowan and Walker, 1979) and the southern extent of the California Current off Baja California (JiménezPérez and Lavaniegos, 2004; Longhurst, 1967) where there is a strong OMZ. Mesopelagic copepod distributions in other strong OMZs worldwide have also been detailed in the Eastern Tropical South Pacific off Peru and Chile (Escribano et al., 2009; Judkins, 1980; Tutasi and Escribano, 2020), the southeastern Atlantic (Bode et al., 2018; Teuber et al., 2013a, b, 2019), and the Arabian Sea (Smith and Madhupratap, 2005; Wishner et al., 2008).

Many earlier zooplankton studies did not collect the comprehensive hydrographic data available from modern electronic CTD and oxygen sensors, did not sample and target 
specific oxyclines and fine-scale vertical strata with precision control, did not extend to deeper mesopelagic depths, or occurred before the recent perspective of OMZ deoxygenation impacts that guides present research (Breitburg et al., 2018). It is also essential to have species-level and life stage identification (not just biomass, size class, or large taxonomic grouping) to understand the multifaceted interactions and evolutionary adaptations of diverse zooplankton to the strong persistent (but variable) oxygen gradients of OMZs. OMZ oxygen is far more variable spatially and temporally than is generally appreciated, even at mesopelagic depths (Fig. 2), and copepod distributions responded to both large and subtle differences.

The physical oceanographic complexity of oxygen distributions and sources in the ETNP, including spatial and temporal variability, has also long been an active topic of investigation (e.g., Deutsch et al., 2011; Fiedler and Talley, 2006; Margolskee et al., 2019; Wishner et al., 2018). However, although we compared vertical distribution differences relative to oxygen gradients among locations and cruises, our sampling was not designed to elucidate responses to the many other spatially and temporally variable environmental forces pertinent to this region, such as climate cycles (El NiñoSouthern Oscillation) or the dynamic variability of the major regional ocean currents or deep advective flow (Kessler, 2006).

\subsection{OMZ, oxycline, and "hypoxiphilic" taxa}

Oxycline-associated and OMZ species showed a remarkable ability to alter their vertical distributions to conform to different oxygen profile shapes at different locations. Many taxa had very narrow oxygen habitat ranges and strong layering, indicative of precise habitat preference and exceptional tolerance for low oxygen. These species tended to alter depth (and temperature) while maintaining a relatively constant oxygen level (Table 3). Important caveats overall are that (1) we focused primarily on adults (except for species previously noted) and (2) total population distributions, even for adults, often extended over broader depth and oxygen ranges beyond the DMA.

We propose the term "hypoxiphilic" to describe species whose population distributions, especially maximum abundances, are focused in habitats with very low oxygen. This term is best used in a comparative sense (without an exact oxygen definition) to allow flexibility for use in other regions and ecological situations and with other taxa, since we know little about the in situ low-oxygen physiology of many species (Teuber et al., 2013b; Thuesen et al., 1998). L. hulsemannae is the most obvious hypoxiphilic copepod (both adults and young stages living in very low oxygen at multiple locations here and in prior work). Earlier studies of its gut contents indicated recent omnivory (Gowing and Wishner, 1992), suggesting active feeding, as well as growth, in this habitat. Other possible hypoxiphilic copepods in this area at this time included D. palumbii, G. kruppi, E. magnus, E. spinifer, diapausing stages of E. inermis, and M. brevicauda adults, but less is known about the vertical and geographic distributional variability of all life history stages for these species.

\subsection{Diapausing in the $\mathrm{OMZ}$}

E. inermis is endemic to the ETP, occurring both north and south of the Equator (Chen, 1986; Fleminger, 1973; Goetze, 2003, 2010; Goetze and Ohman, 2010; Hidalgo et al., 2005a, b; Jackson and Smith, 2016; Sameoto, 1986). It is known to inhabit extremely low oxygen water (Boyd et al., 1980; Escribano et al., 2009; Judkins, 1980; Saltzman and Wishner, 1997; Wishner et al., 2013), as well as oxygenated depths, and has unique physiological and biochemical adaptations for the low-oxygen environment (Cass et al., 2014; Cass and Daly, 2015). Overall population distributions at particular locations in this and prior work usually encompassed a range of oxygen concentrations, although most earlier studies had relatively broad sampling strata that did not isolate specific oxygen ranges or did not have electronic oxygen sensors colocated on the zooplankton sampling systems. DVM by this species, usually over a relatively short depth range between the near surface and UO, was reported by some authors at some times and places but not others (Escribano et al., 2009; Jackson and Smith, 2016). We previously identified apparent diapause layers at the upper and lower OMZ boundaries at the CRD and TB stations in 2007-2008 (Wishner et al., 2013), and Saltzman and Wishner (1997), Sameoto (1986), and Vinogradov et al. (1991) also noted abundance peaks associated with OMZ edges in the CRD and other ETNP locations. Diapause layers in our study varied in depth at different times and stations, allowing the copepods to remain in a constant-low-oxygen habitat.

Use of extremely low oxygen habitats for diapause is likely a predator avoidance mechanism during an extended period of inactivity. Metabolic adaptations that enable longterm survival for copepods in this habitat, while not specifically studied, likely include metabolic suppression and fuel (lipid) storage. Metabolic suppression, typically triggered by epigenetic mechanisms facilitated by microRNAs, enables a variety of animals to survive temporary resource limitation and involves shutting down energetically costly processes such as translation and transcription, ion transport and protein synthesis (Biggar and Storey, 2010; Storey and Storey, 2004). The high proportion of animals with stored oil in these remarkably sharp narrow monospecific layers, composed primarily of adult females and older copepodite stages, were strong indicators of diapause. No obvious gut contents were visually noted in these specimens. E. inermis that was collected at all depths at CRD and TB had stable isotope signatures indicative of feeding at the surface and not on deeper material (Williams et al., 2014), suggesting inactivity at depth. The seasonal ontogenetic and reproductive cy- 
cle of E. inermis was documented at a location off Chile, but the sampling depth was too shallow $(75 \mathrm{~m})$ to elucidate deeper diapause behavior (Hidalgo et al., 2005a, b). Another calanoid copepod, Calanus pacificus, also has an apparent diapause layer just above the anoxic bottom water of the deep Santa Barbara Basin off California (Alldredge et al., 1984; Osgood and Checkley, 1997) and Calanoides carinatus in the Arabian Sea and Benguela Current diapauses at depth just below the extensive OMZ (Auel and Verheye, 2007; Smith et al., 1998; Smith, 1982; Wishner et al., 2008).

\subsection{Diel vertical migration into low oxygen}

Species in the genus Pleuromamma have been studied intensively in the ETNP with regard to their extensive DVM into low-oxygen water, as previously noted. However, unlike resident oxycline and OMZ core taxa, these species appeared to require a period of time at night in well-oxygenated water, presumably to pay off the oxygen debt incurred during daytime residence in low oxygen. It was surprising that the part of their diel distribution that changed with differing oxygen profiles was the shallow nighttime depth, not the deep daytime depth. They continued to migrate to the same depth in the day at different locations, presumably determined by light penetration, and likely an avoidance response to visual predators (Wishner et al., 2013). At night, they came up only until they encountered the depth at which there was sufficient oxygen, within or just above the thermocline, although the temperature was higher at their nighttime depth when the thermocline was shallow, and metabolic costs would be elevated. The thermocline was also usually a peak of zooplankton biomass (Wishner et al., 2013) and fluorescence (Fig. 2), so food was abundant there as well. Thus, the upper nighttime depth likely resulted from the combination of higher oxygen, food availability, and avoidance of even higher temperature in shallower waters.

Pleuromamma species traveled over different depth ranges within low-oxygen water to their daytime depth at the different stations. Our sampling could not resolve whether they moved faster or took longer to make the journey when the depth range was greater, i.e., how long an individual resided in the low-oxygen water in different circumstances and what the comparative metabolic costs might be for the migration. It is also unknown whether all of these species undergo metabolic suppression when in low oxygen, as do many euphausiids and other strong migrators (Seibel et al., 2016, 2018). Teuber et al. (2013a, b, 2019) found that Pleuromamma species in the eastern tropical Atlantic had high thermal and hypoxia tolerances and classified these species as adaptive migrants on the basis of functional traits. Active transport by diel vertical migrators is a critical mechanism of export flux in the CRD (Stukel et al., 2018), and export fluxes appear to be relatively inefficient in locations with OMZs (Berelson et al., 2015). Strong presence-absence differences among stations, especially for Pleuromamma, suggested that some locations may have exceeded the metabolic capabilities of particular species of diel vertical migrators, which could be a factor affecting export flux.

\subsection{Aerobic habitat compression and epipelagic copepods}

The aerobic habitat compression hypothesis was supported by the distributional shifts of several abundant epipelagic species that occurred over a broader depth range at stations where the well-oxygenated mixed layer extended deeper. However, our sampling strata, which focused on the mesopelagic, did not resolve small-scale details, such as short DVM within the mixed layer or thermocline. Additionally, our taxonomic focus on adults of larger easily identified species excluded numerous smaller epipelagic copepods and immature stages. Higher-resolution mixed layer sampling and more taxonomic breadth is required to thoroughly address this issue for ETNP copepods. The high oxygen concentration within the mixed layer would not be a metabolic constraint, but, of course, many other ecological factors could affect distributions.

\subsection{Metabolic implications}

Animal metabolic rates are highly variable depending on physical factors, including temperature and oxygen, as well as on the ecological and evolutionary requirements for energy to support growth, reproduction, predator-prey interactions, and basic maintenance (Seibel and Drazen, 2007). The factorial aerobic metabolic scope (FAS, the maximum as a factor of minimum metabolic rate) typically ranges from about 2 to 6, depending on temperature (Killen et al., 2016; Seibel and Deutsch, 2019). The FAS at any given temperature can be estimated as the ratio of environmental $\mathrm{PO}_{2}$ (below the $P_{\text {crit }}$ for maximum metabolic rate) to the $P_{\text {crit }}$ for resting metabolic rate, which is numerically equivalent to the metabolic index described by Deutsch et al. (2015). This means that the maximum available environmental $\mathrm{PO}_{2}$ is usually a factor of 2-6 above the critical $\mathrm{PO}_{2}$ for resting metabolism, depending on temperature.

For species exposed to air-saturated water, including vertical migrators during their nighttime forays into shallow water, any reduction in $\mathrm{PO}_{2}$ will result in a quantifiable reduction in maximum capacity and FAS. In this light, our observations that the nighttime depth distribution of vertical migrators responded more strongly to variations in oxygen content than did the deeper daytime depth are not surprising. Migrators descend during the day to depths consistent with predator avoidance in low light. If the oxygen at those depths is below the $P_{\text {crit }}$, then metabolic suppression is triggered, which dramatically increases tolerance time to low oxygen (Seibel et al., 2014, 2016, 2018).

In contrast, permanent residents of the lower oxycline and OMZ core have much lower $P_{\text {crit }}$ values. L. hulsemannae, 
for example, has the lowest $P_{\text {crit }}$ ever measured for an animal (minimum values of 0.1 and $0.3 \mathrm{kPa}$; mean values of 0.38 and $0.67 \mathrm{kPa}$ at 8 and $5^{\circ} \mathrm{C}$, respectively), comparable to only two other known OMZ specialists, the pelagic red crab, Pleuroncodes planipes (Quetin and Childress, 1976), and the shrimp, Gennades spp. (Wishner et al., 2018). Using the minimum values and assuming a typical FAS ranging from 2 to 6 (Seibel and Deutsch, 2019; Killen et al., 2016), we suggest that the maximum available environmental $\mathrm{PO}_{2}$ to which L. hulsemannae is ever exposed is $\sim 1.8 \mathrm{kPa}$ at $5^{\circ} \mathrm{C}$ and $\sim 0.6 \mathrm{kPa}$ at $8{ }^{\circ} \mathrm{C}$. These values are very close to the highest values at which $L$. hulsemannae was captured in the present study. The minimum oxygen pressures recorded across the habitat for L. hulsemannae $(0.77$ to $0.30 \mathrm{kPa}$ at different locations) are very near the mean $P_{\text {crit }}$ values and about $2-3 \times$ the minimum $P_{\text {crit }}$ values, thus providing little aerobic scope at those depths. The reverse temperature effect observed for L. hulsemannae, in which higher temperature results in a lower $P_{\text {crit }}$ despite a higher metabolic rate, ensures a FAS similar to that known to bound the latitudinal distributions of many marine species (Deutsch et al., 2015). The reverse temperature effect is adaptive in the lower oxycline of the OMZ where temperature decreases while oxygen increases with increasing depth.

The unique metabolic adaptations for hypoxia tolerance of L. hulsemannae, especially its reverse temperature response, result in a nearly constant ratio ( $\sim 1$ to 2$)$ of environmental $\mathrm{PO}_{2}$ to the mean $P_{\text {crit }}$ across the inhabited depth range. In fact, Wishner et al. (2018) showed that when this ratio (the metabolic index; Deutsch et al., 2015) approaches 2, abundance declines. Using the minimum, rather than the mean, values measured for $L$. hulsemannae suggests higher ratios ( 2-6), which may better represent the in vivo abilities of the species and is more consistent with values shown to support marine animal populations (Deutsch et al., 2015). A ratio below 1 suggests that the species is incapable of meeting its resting needs, whereas a ratio above 1 allows a proportional increase in the scope for aerobic activities, including locomotion, growth, and reproduction. The minimum $\mathrm{PO}_{2}$ at the minimum temperatures reported at all stations results in a drop in the metabolic index consistently below 1 (using mean values). Although our sampling regime cannot pinpoint the precise conditions under which individual animals are found, the metabolic index suggests that this species may not be able to tolerate the most extreme low oxygen at low temperature. Because critical $\mathrm{PO}_{2}$ and its temperature sensitivity vary considerably among species, it is not possible to estimate metabolically available habitat for species lacking $P_{\text {crit }}$ data or those for which data exist at only a single temperature.

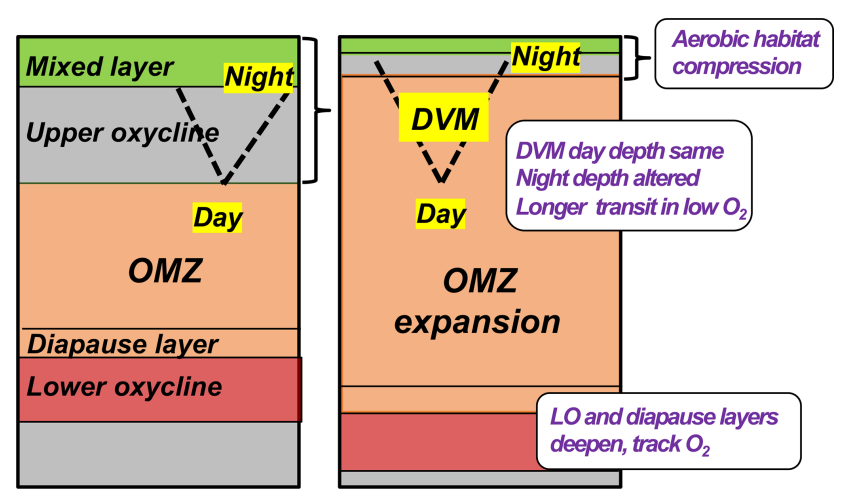

Figure 11. Schematic illustration of OMZ expansion effects on zooplankton distributions. The bracket indicates the most aerobic habitat of the water column (mixed layer plus upper oxycline). The dashed line represents diel vertical migration. The layer of diapausing E. inermis is shown just above the lower oxycline. This figure updates earlier depictions (Seibel, 2011; Wishner et al., 2013; Seibel and Wishner, 2019) with new information from this study.

\section{Conclusions}

Individual copepod species demonstrated different distributional strategies in response to present-day variability of oxygen vertical profiles in the ETNP region. We identified sets of species that (1) changed their vertical distributions and depth of maximum abundance associated with the depth and intensity of the OMZ and its oxycline inflection points; (2) adjusted their diel vertical migration, especially the nighttime upper depth; (3) shifted their depth of diapause; (4) or expanded/contracted their depth range within the mixed layer and upper thermocline in association with the thickness of the aerobic epipelagic zone (Table 2). Congeners, closely related species in the same genus, often showed similar adaptation strategies that were centered at different depths. Hypoxiphilic species had their highest abundances in low-oxygen habitats. These species examples represented a range of calanoid copepod families and trophic ecologies. We expect that similar distributional adaptations to OMZ variability occur across a broad suite of copepod groups, as well as other zooplankton and fish taxa. The schematic diagram Fig. 11 depicts potential zooplankton distributional responses to OMZ expansion, based on present-day patterns.

Combinations of environmental oxygen concentration and temperature, two critical determinants of metabolic rates, defined habitats with the highest abundances for each species at each site. In different locations, animals living at, or transiting through, the same depth (same temperature) could experience quite different oxygen regimes: for example, the daytime migration paths of Pleuromamma species. Animals requiring a specific oxygen partial pressure might be forced to live at different depths (and temperatures): for example, the lower oxycline copepod $L$. hulsemannae and thermocline inhabitant $H$. longicornis. Thus, animals at locations with dif- 
ferent oxygen profiles experienced different oxygen regimes, but the same temperature, at a particular mesopelagic depth, while animals whose peak distributions varied in depth experienced different temperature regimes often at the same oxygen level. Previous work demonstrated that zooplankton can and do respond to very small oxygen and temperature differences in both oceanic and coastal locations (Pierson et al., 2017; Roman et al., 2019; Svetlichny et al., 2000; Wishner et al., 2018). Of course, many other ecological and environmental conditions affect habitat choice and population abundance, but it is likely that the extremely low oxygen of the ETNP OMZ is a critical controlling factor in this region.

As is becoming apparent from numerous studies, the upper ocean to mesopelagic depth range is a complex interwoven ecosystem with intricate relationships among its various inhabitants and their environment. It is also a critically important zone for oceanic biogeochemical and export processes that can be affected by oxygen gradients and hosts key food web components for commercial fisheries. Among the zooplankton, there will likely be winners and losers as ocean deoxygenation continues in the future and becomes more widespread. Changes in individual copepod species abundances, vertical distributions, and life history strategies may create perturbations to these intricate food webs and processes. For example, hypoxiphilic taxa, such as L. hulseman$n a e$, as well as the other oxycline and OMZ species, might increase in abundance and expand their depth range until other physiological (temperature) or ecological (food, predators) barriers become overwhelming. Present-day variability provides a window into future scenarios (Fig. 11), but much more research is required to fully elucidate and quantify consequences.

Data availability. All data needed to evaluate the conclusions in the paper are present in the paper and in two online repositories: the supplementary Table S1 that includes copepod species abundances in each net for these tows (Wishner et al., 2019, https://doi.org/10.23860/dataset-wishner-2019) and the BCO-DMO repository that includes time and location data for each MOCNESS tow, https://www.bco-dmo.org (last access: 20 January 2020), https://doi.org/10.1575/1912/bco-dmo.786098.1 (Wishner, 2020a), and https://doi.org/10.1575/1912/bco-dmo.787329.1 (Wishner, 2020b).

Upon publication, the full paper will be deposited in the BCO-DMO database (with a DOI), as required for National Science Foundation-funded projects. Extensive files of continuous hydrographic data from MOCNESS tows are available from Karen F. Wishner. Additional data related to this paper may be requested from the authors.

Supplement. The supplement related to this article is available online at: https://doi.org/10.5194/bg-17-2315-2020-supplement.
Author contributions. KFW led the writing effort, with substantial contributions from all co-authors. KFW directed the MOCNESS sampling component including analyses of zooplankton abundances and distributions, with assistance at sea and in the lab by all coauthors. DO sorted and identified most of the copepods and processed and graphed data. BAS directed the metabolic sampling and experiments at sea and led the analyses and writing of those sections of the paper.

Competing interests. The authors declare that they have no conflict of interest.

Special issue statement. This article is part of the special issue "Ocean deoxygenation: drivers and consequences - past, present and future (BG/CP/OS inter-journal SI)". It is a result of the International Conference on Ocean Deoxygenation, Kiel, Germany, 3-7 September 2018.

Acknowledgements. We thank the captains, crews, and marine technicians of all the ships and the institutional marine offices (University of Miami, Woods Hole Oceanographic Institution, University of Washington, University of Alaska). MOCNESS instruments and technical support were provided by the University of Miami and Scripps Institution of Oceanography, with assistance from Erich Horgan, James Lovin, Peter Wiebe, Carl Matson, and John Calderwood. Kendra Daly and Brad Seibel served as cruise chief scientists. Many students, technicians, and colleagues helped at sea and in the lab over the years with the MOCNESS tows, sample processing, and data analyses, especially Thomas J. Adams, Nicole Charriere, Kendra Daly, Curtis Deutsch, Charles Flagg, Sarah Frazar, Jason Graff, Jamie Ivory, Amy Maas, Jillon McGreal, Marianne McNamara, Megan O’Brien, Danielle Moore, Jocelyn Pelser, Brennan Phillips, Shannon Riley, Chris Roman, C. Tracy Shaw, and Rebecca Williams.

Financial support. This research has been supported by $\mathrm{Na}-$ tional Science Foundation grants OCE0526545 (Kendra Daly), OCE0526502 (Karen F. Wishner, Brad Seibel), OCE1459243 (Brad Seibel, Karen F. Wishner, Chris Roman), and OCE1458967 (Curtis Deutsch). The University of Rhode Island's Graduate School of Oceanography's summer REU program, SURFO, funded Sarah Frazar and Shannon Riley (NSF grants OCE-0851794 and OCE1460819) and the Coastal Institute contributed to publication costs. Faculty and student funding was also provided by our institutions.

Review statement. This paper was edited by Kenneth Rose and reviewed by two anonymous referees. 


\section{References}

Alldredge, A. L., Robison, B. H., Fleminger, A., Torres, J. J., King, J. M., and Hamner, W. M.: Direct sampling and in situ observation of a persistent copepod aggregation in the mesopelagic zone of the Santa Barbara Basin, Mar. Biol., 80, 75-81, 1984.

Ambler, J. W. and Miller, C. B.: Vertical habitat-partitioning by copepodites and adults of subtropical oceanic copepods, Mar. Biol., 94, 561-577, 1987.

Auel, H. and Verheye, H. M.: Hypoxia tolerance in the copepod Calanoides carinatus and the effect of an intermediate oxygen minimum layer on copepod vertical distribution in the northern Benguela Current upwelling system and the Angola-Benguela Front, J. Exp. Mar. Biol. Ecol., 352, 234-243, https://doi.org/10.1016/j.jembe.2007.07.020, 2007.

Berelson, W. M., Haskell, W. Z., Prokopenko, M., Knapp, A. N., Hammond, D. E., Rollins, N., and Capone, D. G.: Biogenic particle flux and benthic remineralization in the Eastern Tropical South Pacific, Deep-Sea Res. Pt. 1, 99, 23-34, https://doi.org/10.1016/j.dsr.2014.12.006, 2015.

Biggar, K. K. and Storey, K. B.: The emerging roles of microRNAs in the molecular responses of metabolic rate depression, J. Mol. Cell. Biol., 3, 167-175, 2010.

Birk, M. A., Mislan, K. A. S., Wishner, K. F., and Seibel, B. A.: Metabolic adaptations of the pelagic octopod Japetella diaphana to oxygen minimum zones, Deep-Sea Res. Pt. 1, 148, 123-131, 2019.

Bode, M., Hagen, W., Cornils, A., Kaiser, P., and Auel, H.: Copepod distribution and biodiversity patterns from the surface to the deep sea along a latitudinal transect in the eastern Atlantic Ocean $\left(24^{\circ} \mathrm{N}\right.$ to $\left.21^{\circ} \mathrm{S}\right)$, Prog. Oceanogr., 161, 66-77, 2018.

Boyd, C. M., Smith, S. L., and Cowles, T. J.: Grazing patterns of copepods in the upwelling system off Peru, Limnol. Oceanogr., 25, 583-596, 1980.

Breitburg, D., Levin, L. A., Oschlies, A., Grégoire, M., Chavez, F. P., Conley, D. J., Garçon, V., Gilbert, D., Gutiérrez, D., Isensee, K., Jacinto, G. S., Limburg, K. E., Montes, I., Naqvi, S. W. A., Pitcher, G. C., Rabalais, N. N., Roman, M. R., Rose, K. A., Seibel, B. A., Telszewski, M., Yasuhara, M., and Zhang, J.: Declining oxygen in the global ocean and coastal waters, Science, 359, eaam7240, https://doi.org/10.1126/science.aam7240, 2018.

Cass, C. J. and Daly, K. L.: Eucalanoid copepod metabolic rates in the oxygen minimum zone of the eastern tropical north Pacific: Effects of oxygen and temperature, Deep-Sea Res. Pt. 1, 94, 137$149,2014$.

Cass, C. J. and Daly, K. L.: Ecological characteristics of eucalanoid copepods of the eastern tropical North Pacific Ocean: Adaptations for life within a low oxygen system, J. Exp. Mar. Biol. Ecol., 468, 118-129, 2015.

Cass, C. J., Daly, K. L., and Wakeham, S. G.: Assessment of storage lipid accumulation patterns in eucalanoid copepods from the eastern tropical Pacific Ocean, Deep-Sea Res. Pt. 1, 93, 117-130, 2014.

Chen, Y.-Q.: The vertical distribution of some pelagic copepods in the eastern tropical Pacific, CalCOFI Report, 27, 205-227, 1986.

Childress, J. J.: The respiratory rates of midwater crustaceans as a function of depth of occurrence and relation to the oxygen minimum layer off southern California, Comp. Biochem. Phys. A, 50, 787-799, 1975.
Childress, J. J. and Seibel, B. A.: Life at stable low oxygen levels: adaptations of animals to oceanic oxygen minimum layers, J. Exp. Biol., 201, 1223-1232, 1998.

Décima, M., Landry, M. R., Stukel, M. R., Lopez-Lopez, L., and Krause, J. W.: Mesozooplankton biomass and grazing in the Costa Rica Dome: amplifying variability through the plankton food web, J. Plankton Res., 38, 317-330, https://doi.org/10.1093/plankt/fbv091, 2016.

Deutsch, C., Brix, H., Ito, T., Frenzel, H., and Thompson, L.: Climate-forced variability of ocean hypoxia, Science, 333, 336339, https://doi.org/10.1126/science.1202422, 2011.

Deutsch, C., Ferrel, A., Seibel, B., Pörtner, H.-O., and Huey, R. B.: Climate change tightens a metabolic constraint on marine habitats, Science, 348, 1132-1135, https://doi.org/10.1126/science.aaa1605, 2015.

Escribano, R., Hidalgo, P., and Krautz, C.: Zooplankton associated with the oxygen minimum zone system in the northern upwelling region of Chile during March 2000, Deep-Sea Res. Pt. 2, 56, 1083-1094, https://doi.org/10.1016/j.dsr2.2008.09.009, 2009.

Fernández-Álamo, M. A. and Färber-Lorda, J.: Zooplankton and the oceanography of the eastern tropical Pacific: A review, Prog. Oceanogr., 69, 318-359, https://doi.org/10.1016/j.pocean.2006.03.003, 2006.

Ferrari, F. D. and Saltzman, J.: Pleuromamma johnsoni, a new looking-glass copepod from the Pacific Ocean with redescriptions of $P$. robusta (Dahl, 1893), P. antarctica Steuer, 1931 new rank, and P. scutullata Brodskii, 1950 (Crustacea, Calanoida, Metridinidae), Plank. Biol. Ecol., 45, 203-223, 1998.

Fiedler, P. C.: The annual cycle and biological effects of the Costa Rica Dome, Deep-Sea Res. Pt. 1, 49, 321-338, https://doi.org/10.1016/S0967-0637(01)00057-7, 2002.

Fiedler, P. C. and Talley, L. D.: Hydrography of the eastern tropical Pacific: A review, Prog. Oceanogr., 69, 143-180, https://doi.org/10.1016/j.pocean.2006.03.008, 2006.

Fleminger, A.: Pattern, number, variability, and taxonomic significance of integumental organs (sensilla and glandular pores) in the genus Eucalanus (Copepoda, Calanoida), Fish. Bull., 71, 9651010, 1973.

Goetze, E.: Cryptic speciation on the high seas; global phylogenetics of the copepod family Eucalanidae, P. Roy. Soc. Lond. B Bio. 270, 2321-2331, 2003.

Goetze, E.: Species discovery in marine planktonic invertebrates through global molecular screening, Mol. Ecol., 19, 952-967, 2010.

Goetze, E. and Ohman, M. D.: Integrated molecular and morphological biogeography of the calanoid copepod family Eucalanidae, Deep-Sea Res. Pt. 2, 57, 2110-2129, https://doi.org/10.1016/j.dsr2.2010.09.014, 2010.

Gowing, M. M. and Wishner, K. F.: Feeding ecology of benthopelagic zooplankton on an eastern tropical Pacific seamount, Mar. Biol., 112, 451-467, 1992.

Haury, L. R.: Vertical distribution of Pleuromamma (copepoda: Metridinidae) across the eastern north Pacific Ocean, Hydrobiologia, 167, 335-342, 1988.

Hidalgo, P., Escribano, R., and Morales, C. E.: Annual life cycle of the copepod Eucalanus inermis at a coastal upwelling site off Mejillones $\left(23^{\circ} \mathrm{S}\right)$, northern Chile, Mar. Biol., 146, 995-1003, https://doi.org/10.1007/s00227-004-1487-3, 2005a. 
Hidalgo, P., Escribano, R., and Morales, C. E.: Ontogenetic vertical distribution and diel migration of the copepod Eucalanus inermis in the oxygen minimum zone off northern Chile $\left(20-21^{\circ} \mathrm{S}\right)$, J. Plankton Res., 27, 519-529, https://doi.org/10.1093/plankt/fbi025, 2005b.

Hirai, J., Tsuda, A., and Goetze, E.: Extensive genetic diversity and endemism across the global range of the oceanic copepod Pleuromamma abdominalis, Prog. Oceanogr., 138, 77-90, 2015.

Jackson, M. L. and Smith, S. L.: Vertical distribution of Eucalanoid copepods within the Costa Rica Dome area of the Eastern Tropical Pacific, J. Plankton Res., 38, 305-316, https://doi.org/10.1093/plankt/fbv117, 2016.

Jiménez-Pérez, L. C. and Lavaniegos, B. E.: Changes in dominance of copepods off Baja California during the 1997-1999 El Niño and La Niña, Mar. Ecol.-Prog. Ser., 277, 147-165, 2004.

Judkins, D. C.: Vertical distribution of zooplankton in relation to the oxygen minimum off Peru, Deep-Sea Res. Pt. A, 27, 475-487, 1980.

Karstensen, J., Stramma, L., and Visbeck, M.: Oxygen minimum zones in the eastern tropical Atlantic and Pacific oceans, Prog. Oceanogr., 77, 331-350, https://doi.org/10.1016/j.pocean.2007.05.009, 2008.

Kessler, W. S.: The circulation of the eastern tropical Pacific: A review, Prog. Oceanogr., 69, 181-217, https://doi.org/10.1016/j.pocean.2006.03.009, 2006.

Killen, S. S., Glazier, D. S., Rezende, E. L., Clark, T. D., Atkinson, D., Willener, A. S., and Halsey, L. G.: Ecological influences and morphological correlates of resting and maximal metabolic rates across teleost fish species, Am. Nat., 187, 592-606, 2016.

Landry, M. R., Al-Mutairi, H., Selph, K. E., Christensen, S., and Nunnery, S.: Seasonal patterns of mesozooplankton abundance and biomass at Station ALOHA, Deep-Sea Res. Pt. 2, 48, 2037 2061, 2001.

Landry, M. R., De Verneil, A., Goes, J. I., and Moffett, J. W.: Plankton dynamics and biogeochemical fluxes in the Costa Rica Dome: introduction to the CRD Flux and Zinc Experiments, J. Plankton Res., 38, 167-182, https://doi.org/10.1093/plankt/fbv103, 2016.

Levin, L. A.: Manifestation, drivers, and emergence of open ocean deoxygenation, Annu. Rev. Mar. Sci., 10, 229-260, https://doi.org/10.1146/annurev-marine-121916-063359, 2018.

Longhurst, A. R.: Vertical distribution of zooplankton in relation to the eastern Pacific oxygen minimum, Deep-Sea Res., 14, 51-63, https://doi.org/10.1016/0011-7471(67)90028-9, 1967.

Maas, A. E., Frazar, S. L., Outram, D. M., Seibel, B. A., and Wishner, K. F.: Fine-scale vertical distribution of macroplankton and micronekton in the Eastern Tropical North Pacific in association with an oxygen minimum zone, J. Plankton Res., 36, 1557-1575, https://doi.org/10.1093/plankt/fbu077, 2014.

Margolskee, A., Frenzel, H., Emerson, S., and Deutsch, C.: Ventilation pathways for the North Pacific Oxygen Deficient Zone, Global Biogeochem. Cy., 33, 875-890, https://doi.org/10.1029/2018GB006149, 2019.

Markhaseva, E. L. and Ferrari, F. D.: New species of Lucicutia and taxonomic status of L. grandis (Copepoda, Calanoida, Lucicutiidae), J. Nat. Hist., 39, 1077-1100, 2005.

McGowan, J. A. and Walker, P. W.: Structure in the copepod community of the North Pacific central gyre, Ecol. Monogr., 49, 195$226,1979$.
Osgood, K. E. and Checkley Jr., D. M.: Seasonal variations in a deep aggregation of Calanus pacificus in the Santa Barbara Basin, Mar. Ecol.-Prog. Ser., 148, 59-69, 1997.

Paulmier, A. and Ruiz-Pino, D.: Oxygen minimum zones (OMZs) in the modern ocean, Prog. Oceanogr., 80, 113-128, https://doi.org/10.1016/j.pocean.2008.08.001, 2009.

Pierson, J. J., Slater, W.-C. L., Elliott, D., and Roman, M. R.: Synergistic effects of seasonal deoxygenation and temperature truncate copepod vertical migration and distribution, Mar. Ecol.-Prog. Ser., 575, 57-68, 2017.

Quetin, L. B. and Childress, J. J.: Respiratory adaptations of Pleuroncodes planipes to its environment off Baja California, Mar Biol., 38, 327-334, https://doi.org/10.1007/BF00391372, 1976.

Razouls, C., de Bovee, F., Kouwenberg, J., and Desreumaux, N.: Diversity and Geographic Distribution of Marine Planktonic Copepods. Sorbonne University, CNRS, available at: http: //copepodes.obs-banyuls.fr/en (last access: 15 December 2019), 2005.

Robinson, C., Steinberg, D. K., Anderson, T. R., Arístegui, J., Carlson, C. A., Frost, J. R., Ghiglione, J.-F., Hernández-León, S., Jackson, G. A., and Koppelmann, R.: Mesopelagic zone ecology and biogeochemistry - a synthesis, Deep-Sea Res. Pt. 2, 57 , 1504-1518, 2010.

Roman, M. R., Brandt, S. B., Houde, E. D., and Pierson, J. J.: Interactive effects of hypoxia and temperature on coastal pelagic zooplankton and fish, Front. Mar. Sci., 6, 139, https://doi.org/10.3389/fmars.2019.00139, 2019.

Saltzman, J. and Wishner, K. F.: Zooplankton ecology in the eastern tropical Pacific oxygen minimum zone above a seamount: 2 . Vertical distribution of copepods, Deep-Sea Res. Pt. 1, 44, 931-954, https://doi.org/10.1016/S0967-0637(97)00006-X, 1997.

Sameoto, D. D.: Influence of the biological and physical environment on the vertical distribution of mesozooplankton and micronekton in the eastern tropical Pacific, Mar. Biol., 93, 263-279, https://doi.org/10.1007/BF00508264, 1986.

Seibel, B. A.: Critical oxygen levels and metabolic suppression in oceanic oxygen minimum zones, J. Exp. Biol., 214, 326-336, https://doi.org/10.1242/jeb.049171, 2011.

Seibel, B. A. and Deutsch, C.: Oxygen supply capacity in animals evolves to meet maximum demand at the current oxygen partial pressure regardless of size or temperature, bioRxiv, 70141, https://doi.org/10.1101/701417, 2019.

Seibel, B. A. and Drazen, J. C.: The rate of metabolism in marine animals: environmental constraints, ecological demands and energetic opportunities, Philos. T. Roy. Soc. B, 362, 2061-2078, 2007.

Seibel, B. A. and Wishner, K. F.: Chapter 8.1 The significance of ocean deoxygenation for mesopelagic communities, in: Ocean Deoxygenation: Everyone's problem - Causes, impacts, consequences and solutions. Gland, edited by: Laffoley, D. and Baxter, J. M., 265-276, xxii+562 pp., IUCN, Switzerland, 2019.

Seibel, B. A., Häfker, N. S., Trübenbach, K., Zhang, J., Tessier, S. N., Pörtner, H.-O., Rosa, R., and Storey, K. B.: Metabolic suppression during protracted exposure to hypoxia in the jumbo squid, Dosidicus gigas, living in an oxygen minimum zone, J. Exp. Biol., 217, 2555-2568, 2014.

Seibel, B. A., Schneider, J. L., Kaartvedt, S., Wishner, K. F., and Daly, K. L.: Hypoxia tolerance and metabolic suppression in oxygen minimum zone euphausiids: Implications for ocean de- 
oxygenation and biogeochemical cycles, Integr. Comp. Biol., 56, 510-523, https://doi.org/10.1093/icb/icw091, 2016.

Seibel, B. A., Luu, B. E., Tessier, S. N., Towanda, T., and Storey, K. B.: Metabolic suppression in the pelagic crab, Pleuroncodes planipes, in oxygen minimum zones, Comp. Biochem. Physiol., 224, 88-97, https://doi.org/10.1016/j.cbpb.2017.12.017, 2018.

Smith, S., Roman, M., Prusova, I., Wishner, K., Gowing, M., Codispoti, L. A., Barber, R., Marra, J., and Flagg, C.: Seasonal response of zooplankton to monsoonal reversals in the Arabian Sea, Deep Sea Res. Pt. 2, 45, 2369-2403, 1998.

Smith, S. L.: The northwestern Indian Ocean during the monsoons of 1979: distribution, abundance, and feeding of zooplankton, Deep-Sea Res. Pt. A, 29, 1331-1353, 1982.

Smith, S. L. and Madhupratap, M.: Mesozooplankton of the Arabian Sea: patterns influenced by seasons, upwelling, and oxygen concentrations, Prog. Oceanogr., 65, 214-239, 2005.

Steinberg, D. K. and Landry, M. R.: Zooplankton and the ocean carbon cycle, Annu. Rev. Mar. Sci., 9, 413-444, https://doi.org/10.1146/annurev-marine-010814-015924, 2017.

Storey, K. B. and Storey, J. M.: Metabolic rate depression in animals: transcriptional and translational controls, Biol. Rev., 79, 207-233, 2004.

Stramma, L., Johnson, G. C., Sprintall, J., and Mohrholz, V.: Expanding oxygen-minimum zones in the tropical oceans, Science, 320, 655-658, https://doi.org/10.1126/science.1153847, 2008.

Stukel, M. R., Décima, M., Landry, M. R., and Selph, K. E.: Nitrogen and isotope flows through the Costa Rica Dome upwelling ecosystem: The crucial mesozooplankton role in export flux, Global Biogeochem. Cy., 32, 1815-1832, 2018.

Svetlichny, L. S., Hubareva, E. S., Erkan, F., and Gucu, A. C.: Physiological and behavioral aspects of Calanus euxinus females (Copepoda: Calanoida) during vertical migration across temperature and oxygen gradients, Mar. Biol., 137, 963-971, 2000.

Teuber, L., Schukat, A., Hagen, W., and Auel, H.: Distribution and ecophysiology of calanoid copepods in relation to the oxygen minimum zone in the eastern tropical Atlantic, PloS one, 8 , e77590, https://doi.org/10.1371/journal.pone.0077590, 2013a.

Teuber, L., Kiko, R., Séguin, F., and Auel, H.: Respiration rates of tropical Atlantic copepods in relation to the oxygen minimum zone, J. Exp. Mar. Biol. Ecol., 448, 28-36, https://doi.org/10.1016/j.jembe.2013.06.012, 2013b.

Teuber, L., Hagen, W., Bode, M., and Auel, H.: Who is who in the tropical Atlantic? Functional traits, ecophysiological adaptations and life strategies in tropical calanoid copepods, Prog. Oceanogr., 171, 128-135, https://doi.org/10.1016/j.pocean.2018.12.006, 2019.

Thuesen, E., Miller, C., and Childress, J.: Ecophysiological interpretation of oxygen consumption rates and enzymatic activities of deep-sea copepods, Mar. Ecol.-Prog. Ser., 168, 95-107, https://doi.org/10.3354/meps168095, 1998.
Tutasi, P. and Escribano, R.: Zooplankton diel vertical migration and downward $\mathrm{C}$ flux into the oxygen minimum zone in the highly productive upwelling region off northern Chile, Biogeosciences, 17, 455-473, https://doi.org/10.5194/bg-17-455-2020, 2020.

Vinogradov, M. E., Shushkina, E. A., Gorbunov, A. E., and Shashkov, N. L.: Vertical distribution of the macro-and mesoplankton in the region of the Costa Rica dome. Distribución vertical del macro y mesoplancton en la región del domo de Costa Rica, Okeanologiya., 31, 559-565, 1991.

Wiebe, P. H., Morton, A. W., Bradley, A. M., Backus, R. H., Craddock, J. E., Barber, V., Cowles, T. J., and Flierl, G.: New development in the MOCNESS, an apparatus for sampling zooplankton and micronekton, Mar. Biol., 87, 313-323, 1985.

Williams, R. L., Wakeham, S., McKinney, R., and Wishner, K. F.: Trophic ecology and vertical patterns of carbon and nitrogen stable isotopes in zooplankton from oxygen minimum zone regions, Deep-Sea Res. Pt. 1, 90, 36-47, https://doi.org/10.1016/j.dsr.2014.04.008, 2014.

Wishner, K.: BCO-DMO: MOCNESS Event Logs (a), WHOAS, https://doi.org/10.1575/1912/bco-dmo.786098.1, 2020a.

Wishner, K.: BCO-DMO: MOCNESS Event Logs (b), WHOAS, https://doi.org/10.1575/1912/bco-dmo.787329.1, 2020b.

Wishner, K., Seibel, B., Roman, C., Deutsch, C., Outram, D., Shaw, C., Birk, M., Mislan, K., Adams, T., Moore, D., and Riley, S.: Ocean deoxygenation and zooplankton: very small oxygen differences matter, Sci. Adv., 4, eaau5180, https://doi.org/10.1126/sciadv.aau5180, 2018.

Wishner, K. F., Gowing, M. M., and Gelfman, C.: Living in suboxia: Ecology of an Arabian Sea oxygen minimum zone copepod, Limnol. Oceanogr., 45, 1576-1593, https://doi.org/10.4319/lo.2000.45.7.1576, 2000.

Wishner, K. F., Gelfman, C., Gowing, M. M., Outram, D. M., Rapien, M., and Williams, R. L.: Vertical zonation and distributions of calanoid copepods through the lower oxycline of the Arabian Sea oxygen minimum zone, Prog. Oceanogr., 78, 163191, https://doi.org/10.1016/j.pocean.2008.03.001, 2008.

Wishner, K. F., Outram, D. M., Seibel, B. A., Daly, K. L., and Williams, R. L.: Zooplankton in the eastern tropical north Pacific: Boundary effects of oxygen minimum zone expansion, Deep-Sea Res. Pt. 1, 79, 122-140, https://doi.org/10.1016/j.dsr.2013.05.012, 2013.

Wishner, K. F., Seibel, B., and Outram, D.: Supplementary Table S1 for Ocean deoxygenation and copepods: Coping with oxygen minimum zone variability, GSO Data Sets, https://doi.org/10.23860/dataset-wishner-2019, 2019. 